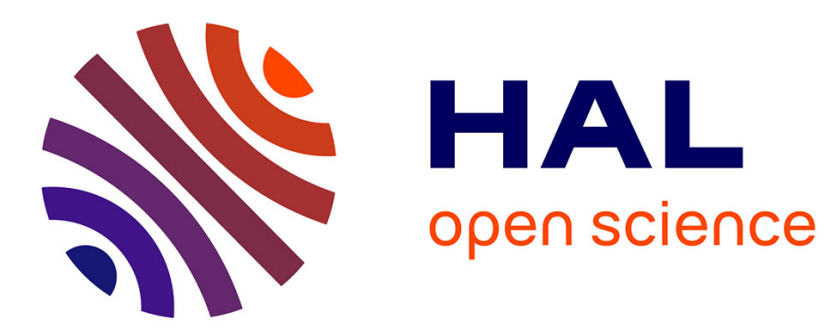

\title{
Cavity induced vibration of flexible hydrofoils
}

Deniz Tolga Akcabay, Eun Jung Chae, Yin Lu Young, Antoine Ducoin, Jacques André Astolfi

\section{To cite this version:}

Deniz Tolga Akcabay, Eun Jung Chae, Yin Lu Young, Antoine Ducoin, Jacques André Astolfi. Cavity induced vibration of flexible hydrofoils. Journal of Fluids and Structures, 2014, 49, pp.463-484. 10.1016/j.jfluidstructs.2014.05.007 . hal-01087334

\section{HAL Id: hal-01087334 https://hal.science/hal-01087334}

Submitted on 25 Nov 2014

HAL is a multi-disciplinary open access archive for the deposit and dissemination of scientific research documents, whether they are published or not. The documents may come from teaching and research institutions in France or abroad, or from public or private research centers.
L'archive ouverte pluridisciplinaire HAL, est destinée au dépôt et à la diffusion de documents scientifiques de niveau recherche, publiés ou non, émanant des établissements d'enseignement et de recherche français ou étrangers, des laboratoires publics ou privés. 


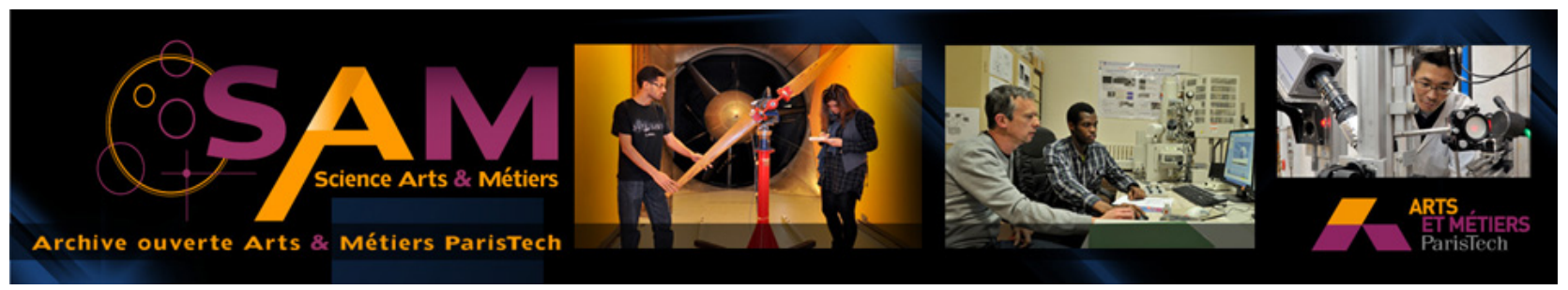

\section{Science Arts \& Métiers (SAM)}

is an open access repository that collects the work of Arts et Métiers ParisTech researchers and makes it freely available over the web where possible.

This is an author-deposited version published in: http://sam.ensam.eu

Handle ID: .http://hdl.handle.net/10985/8992

\section{To cite this version :}

Deniz Tolga AKCABAY, Eun Jung CHAE, Yin Lu YOUNG, Antoine DUCOIN, Jacques André ASTOLFI - Cavity induced vibration of flexible hydrofoils - Journal of Fluids and Structures - Vol. 49, p.463-484 - 2014 


\title{
Cavity induced vibration of flexible hydrofoils
}

\author{
Deniz Tolga Akcabay ${ }^{a}$, Eun Jung Chae ${ }^{a}$, Yin Lu Young ${ }^{a, *}$, \\ Antoine Ducoin ${ }^{\mathrm{a}, \mathrm{b}}$, Jacques Andre Astolfi ${ }^{\mathrm{c}}$
}

a Naval Architecture and Marine Engineering, University of Michigan, Ann Arbor, MI, USA

${ }^{\mathrm{b}}$ LHEEA Laboratory, Ecole Centrale de Nantes, Nantes, France

${ }^{\mathrm{c}}$ French Naval Academy Research Institute (IRENav), Brest Cedex 09, France

Keywords:

Cavitation

Vibration

Lock-in

Hydrofoil

Flexible

Frequency modulation

\begin{abstract}
A B S T R A C T
The objective of this work is to investigate the influence of cavity-induced vibrations on the dynamic response and stability of a NACA66 hydrofoil at $8^{\circ}$ angle of attack at $\operatorname{Re}=750000$ via combined experimental measurements and numerical simulations. The rectangular, cantilevered hydrofoil is assumed to be rigid in the chordwise direction, while the spanwise bending and twisting deformations are represented using a two-degreesof-freedom structural model. The multiphase flow is modeled with an incompressible, unsteady Reynolds Averaged Navier-Stokes solver with the $k-\omega$ Shear Stress Transport (SST) turbulence closure model, while the phase evolutions are modeled with a masstransport equation based cavitation model. The numerical predictions are compared with experimental measurements across a range of cavitation numbers for a rigid and a flexible hydrofoil with the same undeformed geometries. The results showed that foil flexibility can lead to: (1) focusing - locking - of the frequency content of the vibrations to the nearest subharmonics of the foil's wetted natural frequencies, and (2) broadening of the frequency content of the vibrations in the unstable cavitation regime, where amplifications are observed in the sub-harmonics of the foil natural frequencies. Cavitation was also observed to cause frequency modulation, as the fluid density, and hence fluid induced (inertial, damping, and disturbing) forces fluctuated with unsteady cavitation.
\end{abstract}

\section{Introduction}

The recent interest to use lighter and flexible materials for marine structures (e.g. Liu and Young, 2009; Motley et al., 2009; Young, 2008) makes it increasingly important to understand the unsteady fluid-structure interaction (FSI) response and stability of flexible marine structures. A particular subject of interest is unsteady cavitation induced vibrations of flexible marine structures, where the structural dynamics might be strongly coupled with the hydrodynamic cavitation. Cavitation occurs when the local fluid pressure drops to the saturated vapor pressure; this might occur on hydrofoils, rudders, propellers, and turbines during their high-speed and/or off-design operations, particularly near the air-water surface in the absence of high static pressure. The collapse of cavity induced vapor bubbles may produce strong structural vibrations as shown in Franc (2006), which would cause noise, accelerated fatigue, material damage, and even hydroelastic instability issues.

\footnotetext{
* Corresponding author. Tel.: +1 734647 0249; fax: +1 7349368820 .

E-mail address: ylyoung@umich.edu (Y.L. Young).
} 


\begin{tabular}{|c|c|c|c|}
\hline \multicolumn{2}{|c|}{ Nomenclature } & \multirow{2}{*}{$\begin{array}{l}\bar{h} \\
I^{\prime}\end{array}$} & \multirow{3}{*}{$\begin{array}{l}\text { time-dependent part of the hydrofoil bending } \\
\text { displacement } \\
\text { second moment of area of the hydrofoil about } \\
\text { its thickness and about E.A. } \\
\text { hydrofoil's 3-D generalized moment of inertia } \\
\text { along the E.A. }\end{array}$} \\
\hline$A$ & 2-D (per unit span) hydrofoil surface area & & \\
\hline$a$ & $\begin{array}{l}\text { nondimensional distance (as a fraction of } b \text { ) } \\
\text { from the mid-chord position to the E.A. }\end{array}$ & $\tilde{I}_{\theta}$ & \\
\hline $\begin{array}{l}D \\
\text { CFL }\end{array}$ & $\begin{array}{l}\text { halt chord length }(=c / 2) \\
\text { Courant-Friedrichs-Lewy number }\end{array}$ & $I_{\theta}^{\prime}$ & 2-D (per unit span) hydrofoil moment of \\
\hline$\underline{\tilde{C}}$ & generalized structural damping matrix & & inertia along its E.A. \\
\hline$\overline{\tilde{C}}^{T}$ & $\begin{array}{l}\text { potential flow prediction of the generalized } \\
\text { added damping matrix }\end{array}$ & $(\mathbf{i}, \mathbf{j})$ & $\begin{array}{l}\text { unit vectors along }(\mathbf{X}, \mathbf{Y}) \\
\text { time-step index }\end{array}$ \\
\hline$C_{D}$ & drag coefficient & $\begin{array}{l}J^{\prime} \\
K\end{array}$ & $\begin{array}{l}\text { hydrofoil torsion constant } \\
\text { hydrofoil's kinetic energy }\end{array}$ \\
\hline$C_{L}\left(\bar{C}_{L}\right)$ & lift coefficient (mean lift coefficient) & $\tilde{K}$ & generalized structural stiffness matrix \\
\hline $\begin{array}{l}C_{M} \\
C_{\text {cond }} \\
C_{\text {evap }}\end{array}$ & $\begin{array}{l}\text { moment coefficient about the foil E.A. } \\
\text { empirical condensation rate constant } \\
\text { empirical evaporation rate constant }\end{array}$ & $\underline{\tilde{K}}^{T}$ & $\begin{array}{l}\text { potential flow prediction of the generalized } \\
\text { added stiffness matrix }\end{array}$ \\
\hline$\tilde{C}_{h}$ & $\begin{array}{l}\text { hydrofoil's damping constant for spanwise } \\
\text { bending }\end{array}$ & $\begin{array}{l}\tilde{K}_{\theta} \\
\tilde{K}_{h}\end{array}$ & $\begin{array}{l}\text { hydrofoil spanwise twisting (torsion) stiffness } \\
\text { hydrofoil spanwise bending stiffness }\end{array}$ \\
\hline$C_{h}^{\prime}$ & $\tilde{C}_{h}$ per unit span & $k$ & reduced frequency $\left(=\omega b / U_{o}\right)$ of the hydrofoil \\
\hline$C_{p}$ & pressure coefficient & $k_{\text {mesh }}$ & variable mesh stiffness \\
\hline$\tilde{C}_{\theta}$ & $\begin{array}{l}\text { hydrofoil's damping constant for spanwise } \\
\text { twisting (torsion) }\end{array}$ & $\begin{array}{l}\tilde{L} \\
L^{\prime}\end{array}$ & $\begin{array}{l}\text { net lift force on the hydrofoil } \\
2-D \text { (per unit span) net lift force on the }\end{array}$ \\
\hline CFD & computational fluid dynamics & $L A$ & Lagrangian $(=K-V)$ of the hydrofoil \\
\hline C.G. & ter of gravity & LE & leadir \\
\hline C.P. & center of pressure & LHC me & hod loose Hybrid Coupled method \\
\hline c & hydrofoil chord length & $l_{c, \max }$ & maximum cavity length \\
\hline$\tilde{D}$ & net drag force on the hydrofoil & $\underline{\tilde{M}}$ & generalized structural mass matrix \\
\hline$D^{\prime}$ & $\begin{array}{l}\text { 2-D (per unit span) net drag force on the } \\
\text { hydrofoil }\end{array}$ & $\overline{\tilde{M}}^{T}$ & $\begin{array}{l}\text { potential flow prediction of the generalized } \\
\text { added mass matrix }\end{array}$ \\
\hline $\begin{array}{l}\mathrm{DU} \\
E_{s}\end{array}$ & Young's modulus of the hydrofoil & $\tilde{m}$ & hydrofoil's 3-D generalized mass \\
\hline E.A. & elastic axis & $m^{\prime}$ & 2-D (per unit span) mass of the hydrofoil \\
\hline EOM & equations of motion & $\dot{m}_{\text {cond }}$ & condensation rate of the vapor \\
\hline & $\begin{array}{l}\text { nondimensional distance (as a fraction of } c \text { ) } \\
\text { from the E.A. to the C.P. }\end{array}$ & $\begin{array}{l}\dot{m}_{\text {evap }} \\
\mathbf{n}\end{array}$ & $\begin{array}{l}\text { evaporation rate of the liquid } \\
\text { unit normal vector on the foil surface pointing }\end{array}$ \\
\hline$\underline{F}_{\text {fluid }}^{I}$ & $\begin{array}{l}\text { potential flow prediction of the fluid forces } \\
\text { acting on the hydrofoil } \\
\text { fluid-structure interaction }\end{array}$ & $n$ & $\begin{array}{l}\text { exponent used in the empirical relation } \\
\text { between } \mu_{\text {turb }}^{*} \text { and } \mu_{\text {turb }}\end{array}$ \\
\hline FW & fully-wetted & $p$ & local pressure of the liquid/vapor mixture \\
\hline$f$ & normalized bending shape function of the 3-D & $p_{o}$ & $\begin{array}{l}\text { static pressure at the fluid domain outlet } \\
\text { saturated vapor pressure }\end{array}$ \\
\hline & $\begin{array}{l}\text { hydrofoil } \\
\text { cavity shedding frequency }\end{array}$ & $\begin{array}{l}P v \\
R_{B}\end{array}$ & vapor nuclei radius \\
\hline$f_{h}^{a}$ & $\begin{array}{l}\text { hydrofoil's first bending natural frequency in } \\
\text { air }\end{array}$ & $\begin{array}{l}\operatorname{Re} \\
\mathbf{r}\end{array}$ & $\begin{array}{l}\text { Reynolds number } \\
\text { position vector from the E.A. to a point on the }\end{array}$ \\
\hline$f_{h}^{F W}$ & $\begin{array}{l}\text { hydrofoil's first bending natural frequency } \\
\text { in water }\end{array}$ & $s$ & $\begin{array}{l}\text { foil surface } \\
\text { hydrofoil span length }\end{array}$ \\
\hline$f_{h}^{w}$ & $\begin{array}{l}\text { hydrofoil's first bending natural frequency in } \\
\text { water/vapor mixture }\end{array}$ & $\begin{array}{l}s_{f f} \\
s_{f g}\end{array}$ & $\begin{array}{l}=\int_{0}^{s} f(z)^{2} d z \\
=\int_{0}^{s} f(z) g(z) d z\end{array}$ \\
\hline$f_{\theta}^{a}$ & $\begin{array}{l}\text { hydrofoil's first torsion natural frequency in } \\
\text { air }\end{array}$ & $\begin{array}{l}s_{g g} \\
\tilde{T}\end{array}$ & $\begin{array}{l}=\int_{0}^{s} g(z)^{2} d z \\
\text { net fluid-induced moment on the hydrofoil E.A. }\end{array}$ \\
\hline$f_{\theta}^{F W}$ & $\begin{array}{l}\text { hydrofoil's first torsion natural frequency } \\
\text { in water }\end{array}$ & $T^{\prime}$ & $\begin{array}{l}\text { 2-D fluid-induced moment (per unit span) } \\
\text { about the hydrofoil E.A. }\end{array}$ \\
\hline$f_{\theta}^{w}$ & $\begin{array}{l}\text { hydrofoil's first torsion natural frequency in } \\
\text { water/vapor mixture }\end{array}$ & $\begin{array}{l}T_{o} \\
\mathrm{TE}\end{array}$ & $\begin{array}{l}\text { main cavity shedding period } \\
\text { trailing edge }\end{array}$ \\
\hline$G_{s}$ & hydrofoil torsional rigidity & $t$ & time \\
\hline$g$ & $\begin{array}{l}\text { normalized twisting shape function of the 3-D } \\
\text { hydrofoil }\end{array}$ & $\begin{array}{l}U_{o} \\
\text { uRANS }\end{array}$ & $\begin{array}{l}\text { uniform inflow speed along } \mathbf{X} \\
\text { unsteady Reynolds Averaged Navier-Stokes }\end{array}$ \\
\hline $\begin{array}{l}H_{0}^{2}, H_{1}^{2} \\
h\end{array}$ & $\begin{array}{l}\text { Hankel functions } \\
\text { hydrofoil's bending displacement at the E.A. }\end{array}$ & $\mathbf{u}$ & $\begin{array}{l}\text { equations } \\
\text { local velocity of the liquid/vapor mixture }\end{array}$ \\
\hline
\end{tabular}


$u \quad$ local velocity of the liquid/vapor mixture along the $\mathbf{X}$ direction

$u_{\tau} \quad$ estimated friction velocity

$V \quad$ hydrofoil's elastic energy

$v \quad$ local velocity of the liquid/vapor mixture along the $\mathbf{Y}$ direction

$(\mathbf{X}, \mathbf{Y})$ coordinate axis centered at the E.A. of the undeformed hydrofoil

$\left(x_{\theta}, y_{\theta}\right)$ nondimensional distance (as a fraction of $b$ ) from the E.A. to C.G along $\mathbf{X}$ and $\mathbf{Y}$.

\section{$y^{+} \quad=\rho_{l} u_{\tau} y / \mu_{l}$}

$z \quad$ span length parameter, ( $=0$ at the hydrofoil fixed end, $=s$ at the hydrofoil tip)

$\alpha_{\text {nuc }} \quad$ empirical volume fraction of the vapor nuclei sites

$\alpha_{0} \quad$ hydrofoil initial angle of attack

$\alpha_{\text {eff }} \quad$ hydrofoil effective angle of attack

$\alpha_{\text {Lo }} \quad$ hydrofoil's angle of attack at which lift force is zero (camber angle)

$\Delta t \quad$ time-step size

$\delta \quad$ local mesh displacement

$\zeta_{h} \quad$ damping factor for hydrofoil bending in air $\zeta_{\theta} \quad$ damping factor for hydrofoil torsion in air

$\Theta \quad$ Theodorsen's function

$\theta \quad$ hydrofoil's twist-angle displacement along the E.A.

$\bar{\theta} \quad$ time-dependent part of the hydrofoil twistangle displacement along the E.A.

$\mu \quad$ dynamic viscosity of the liquid/vapor mixture

$\mu_{l} \quad$ dynamic viscosity of the liquid

$\mu_{v} \quad$ dynamic viscosity of the vapor

$\mu_{\text {turb }} \quad$ turbulent eddy viscosity of the liquid/vapor mixture adjusted for the presence of cavitation

$\mu_{\text {turb }}^{*}$ turbulent eddy viscosity of the liquid/vapor mixture

$\nu_{S} \quad$ Poisson's ratio of the hydrofoil material

$\rho$ density of the liquid/vapor mixture

$\rho_{l} \quad$ density of the liquid

$\rho_{s} \quad$ density of the hydrofoil material

$\rho_{v} \quad$ density of the vapor

$\sigma \quad$ cavitation number

$\phi \quad$ local volume fraction of the vapor phase $(=1$ pure vapor, $=0$ pure liquid)

$\omega \quad$ primary vibration frequency of the hydrofoil

Cavitation has been a subject of intense research for many decades. Readers could refer to Brennen (1995), Franc (2006), and Franc and Michel (2005) for general descriptions of cavitating flows. In particular, for cavitating flows over hydrofoils, there have been many experimental works e.g. (Arndt, 2012; Arndt and Wosnik, 2008; Franc and Michel, 1988; Kato et al., 2006; Kawakami et al., 2008; Leroux et al., 2004; Sedlar et al., 2012) and theoretical works e.g. (Akcabay et al., 2012; Amromin, 2014; Amromin and Kovinskaya, 2000; Benaouicha et al., 2009; Ducoin et al., 2012b; Harwood et al., 2012; Huang et al., 2013; Huang et al., 2012; Karim et al., 2010; Mostafa et al., 2012; Saito et al., 2007; Sedlar et al., 2012; Seo and Lele, 2009; Sun, 2012; Young, 2007); older past works are mentioned in the review paper of Abramson (1969).

In addition to the above works that have focused on rigid hydrofoils, flexible hydrofoils in cavitating flows were experimentally studied in Ausoni et al. (2007), Besch (1969), Brennen et al. (1980), Ducoin et al. (2012a), Kaplan and Lehman (1966), and Song (1969). Ausoni et al. (2007) observed that if the cavity or vortex shedding frequency comes near the structural natural frequencies, the structural vibration amplitudes would significantly increase and affect the cavity/vortex shedding patterns. A similar coupling was also observed in Kato et al. (2006) between the controlled pitching frequency of a hydrofoil and the cavity breakdown frequency, and it is called 'lock-in'. Kaplan and Lehman (1966), Besch (1969), and Song (1969) experimentally observed that cavitating flows can excite 'flutter-like' vibrations with modest amplitudes on hydrofoils when the cavity length gets close to the hydrofoil chord length. Brennen et al. (1980) have experimentally and theoretically studied the leading-edge flutter condition of a supercavitating hydrofoil. Ducoin et al. (2012a) have experimentally studied the cavitating flow around both a stationary and pitching flexible hydrofoil, and showed that cavitation can excite the wetted natural frequencies of the hydrofoil. In a numerical study, Akcabay and Young (2014) showed that the fluctuating parts of the hydrodynamic loads and deformations can get as big as their mean values under cavitating conditions, especially when the maximum cavity length comes close to the foil chord length. However, Akcabay and Young (2014) also showed that the fluctuations reduce once the cavity length exceeds the chord length and supercavitation forms.

Note that except the few experimental works mentioned above, most of the numerical works thus far have focused primarily on problems with no or weak FSI. Hence, it remains an interesting question to examine how cavitating flows interact with flexible structures. This work and the recent study presented in Akcabay and Young (2014) are one of the first in its kind by introducing a numerical viscous FSI framework along with experimental measurements to study the coupled effects of unsteady cavitating flows and flexible hydrofoils.

The objectives of this work are to (i) simulate cavity-induced vibrations via combined numerical and experimental modeling; and (ii) investigate the influence of foil vibrations on cavity and vorticity dynamics, and resultant load variations. In the present study, the cavity can incept on the hydrofoil surface; in this regard, it differs from the experimental work presented in Ausoni et al. (2007), which had only considered cavitation in the wake of a foil with a blunt trailing edge.

\section{Experimental modeling}

The experimental studies shown in this work were carried out in a cavitation tunnel at the French Naval Academy. The primary characteristics of the experimental set-up are summarized here, and additional information about the instrumentation with experimental uncertainties is available in Ducoin et al. (2012a) and Leroux et al. (2004). 
The experiments involved a rigid and a flexible NACA66 hydrofoil, both with identical undeformed geometries with a chord length, $c$, of $0.15 \mathrm{~m}$, and span length, $s$, of $0.191 \mathrm{~m}$. Both foils had a $12 \%$ maximum thickness-to-chord ratio, and a 0.8 camber distribution with a maximum camber-to-chord length ratio of $2 \%$. The foils were mounted horizontally at midheight of the test section. The test section shown in Fig. 1 is $0.192 \mathrm{~m} \times 0.192 \mathrm{~m} \times 1 \mathrm{~m}$, and the set-up involves a cantilevered hydrofoil with a uniform cross-section that is fixed to a wall at its root through a rigid mounting unit by which its angle of attack could be controlled. There was a $1 \mathrm{~mm}$ clearance $(0.5 \%$ of the foil span) between the free tip of the cantilever hydrofoil and the other end of the tunnel wall. The gap between the hydrofoil tip and the tunnel wall was within the boundary layer of the wall, which limited the effects of finite aspect ratio and tip vortices. The rigid hydrofoil was made of stainless-steel with Young's modulus of $E_{s}=210 \mathrm{GPa}$, density of $\rho_{s}=7800 \mathrm{~kg} / \mathrm{m}^{3}$, and Poisson's ratio of $\nu_{s}=0.3$. The flexible hydrofoil was made of a POM polyacetate with $E_{s}=3 \mathrm{GPa}, \rho_{s}=1480 \mathrm{~kg} / \mathrm{m}^{3}$, and $\nu_{s}=0.35$.

For the flexible hydrofoil experiment, the structural velocities of the hydrofoil vibrations were measured by means of a Laser Doppler Vibrometer Polytec PSV-400, using a Class II He-Ne laser of wavelength $\lambda=633 \mathrm{~nm}$. The device was equipped with a scanning system that enabled vibration measurements over a predefined grid mapped on the vibrating surface. At each measurement point of the grid, the Fourier transform of the vibration velocity signal was computed and was averaged from a user-defined number of acquisitions. The local spectrum was spatially averaged over the grid points to obtain the mean spatial vibration of the foil surface. Additionally, the foil free tip displacement and its spectrum were measured by analyzing images obtained with a BASLER video camera (camera 1 in Fig. 1), with a sampling frequency of about 100 images per second, with an uncertainty of 1 pixel corresponding to $0.07 \mathrm{~mm}$. More information about this instrumentation could be found in Ducoin et al. (2012a).

\section{Numerical modeling}

The simulations used the commercial ANSYS ${ }^{\circledR}$-CFX (version 14.0) (ANSYS, 2011) software as the fluid dynamics solver and an in-house written FORTRAN code to solve for the structural dynamics and to couple it with the fluid dynamics solver. The next subsections detail the fluid, solid, and fluid-structure interaction models.

\subsection{Fluid model}

The flow is assumed to be governed by the incompressible, unsteady Reynolds Averaged Navier-Stokes (uRANS) equations, shown in Eq. (1). This model uses a single set of equations for both the liquid and vapor phases of the water flow, with the mixture density, $\rho$, and mixture viscosity, $\mu$, as defined in Eq. (2). In Eq. (1), $\mu_{\text {turb }}^{*}$ is the turbulence eddy viscosity for the uRANS model, $p$ is pressure, $t$ is time, and $\mathbf{u}$ is the local velocity of the fluid mixture. The effect of the surface tension and gravity are omitted in Eq. (1). In Eq. (2), $\rho_{l}$ and $\rho_{v}$ are respectively the liquid and vapor densities; $\mu_{l}$ and $\mu_{v}$ are respectively

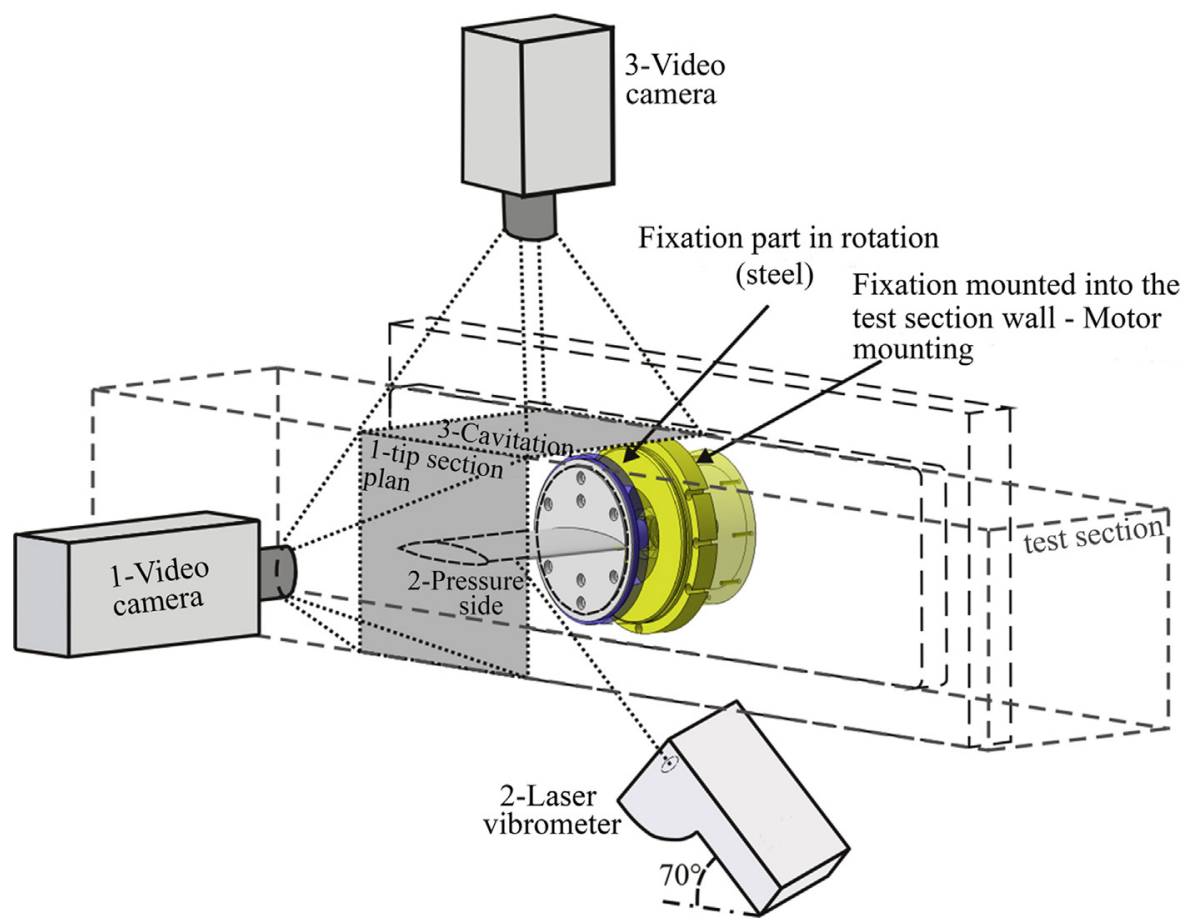

Fig. 1. Experimental set-up in Ducoin et al. (2012a) and Leroux et al. (2004). This figure is re-used with minor adjustments from Ducoin et al. (2012a). 
the liquid and vapor dynamic viscosities; $\phi$ is the local volume fraction of the vapor phase, which is equal to 1 if the fluid is pure vapor and equal to 0 if the fluid is pure liquid.

$$
\begin{aligned}
& \rho\left(\frac{\partial \mathbf{u}}{\partial t}+\mathbf{u} \cdot \nabla \mathbf{u}\right)=-\nabla p+\nabla \cdot\left[\left(\mu+\mu_{\text {turb }}^{*}\right)\left(\nabla \mathbf{u}+\nabla \mathbf{u}^{\mathrm{T}}\right)\right], \\
& \frac{\partial \rho}{\partial t}+\nabla \cdot(\rho \mathbf{u})=0, \\
& \rho=(1-\phi) \rho_{l}+\phi \rho_{v}, \\
& \mu=(1-\phi) \mu_{l}+\phi \mu_{v} .
\end{aligned}
$$

The simulations use the $k-\omega$ Shear Stress Transport (SST) turbulence closure model given in Menter (1992) to obtain $\mu_{\text {turb }}^{*}$ in Eq. (1). However, as noted in Coutier-Delgosha et al. (2003) and Ducoin et al. (2012b), standard turbulence closure models (including the $k-\varepsilon$ and $k-\omega$ models), which are originally developed for single phase flows, tend to overestimate the turbulent eddy viscosity in the cavity region; this can prevent/delay the upstream motion of the re-entrant jet that is typically observed for cavitating flows over hydrofoils, which will lead to different cavity shedding frequencies compared to experimental measurements. Following Coutier-Delgosha et al. (2003) and Reboud et al. (1998), to reduce the turbulent eddy viscosity in the cavity region, and to account for the effect of local compressibility on the turbulent closure model, $\mu_{\text {turb }}^{*}$ in Eq. (1) is replaced with $\mu_{t u r b}$, which is defined in Eq. (3). In this work, $n$ in Eq. (3) is chosen as 3, following recommendations presented in Ducoin et al. (2012b) and Huang et al. (2012).

$$
\mu_{\text {turb }}=\mu_{\text {turb }}^{*} \frac{\rho_{v}+(1-\phi)^{n}\left(\rho_{l}-\rho_{v}\right)}{\rho_{v}+(1-\phi)\left(\rho_{l}-\rho_{v}\right)} .
$$

The evolution and transport of the liquid and vapor phases are determined by Eq. (4) - a mass transport equation in terms of $\phi$, with $\dot{m}_{\text {evap }}$ for the evaporation rate and $\dot{m}_{\text {cond }}$ for the condensation rate.

$$
\frac{\partial\left(\rho_{v} \phi\right)}{\partial t}+\nabla \cdot\left(\rho_{v} \phi \mathbf{u}\right)=-\dot{m}_{\text {cond }}+\dot{m}_{\text {evap }}
$$

The condensation and evaporation rates in Eq. (4) are determined by using the cavitation model presented in Zwart et al. (2004), which was derived by generalizing the first order results for the growth of a single bubble to the whole vapor phase; this approach assumes a constant volume fraction of the vapor nuclei sites $\left(\alpha_{n u c}\right)$ and nuclei radius $\left(R_{B}\right)$, and neglects the effect of bubble-to-bubble interactions.

$$
\begin{aligned}
& \dot{m}_{\text {evap }}=C_{\text {evap }} \frac{3 \alpha_{n u c}(1-\phi) \rho_{v}}{R_{B}} \sqrt{\frac{2}{3} \frac{p_{v}-p}{\rho_{l}}} \text { for } p<p_{v}, \\
& \dot{m}_{\text {cond }}=C_{\text {cond }} \frac{3 \phi \rho_{v}}{R_{B}} \sqrt{\frac{2}{3} \frac{p-p_{v}}{\rho_{l}}} \text { for } p>p_{v} .
\end{aligned}
$$

In Eq. (5), $p_{v}$ is the saturated vapor pressure, while $C_{\text {cond }}$ and $C_{\text {evap }}$ are (nondimensional) empirical constants for the condensation and evaporation rates, respectively. The current simulation uses $R_{B}=2 \times 10^{-6} \mathrm{~m}, \alpha_{\text {nuc }}=5 \times 10^{-4}, C_{\text {cond }}=0.01$, and $C_{\text {evap }}=50$. Validation and convergence studies for these turbulence and cavitation models with the selected constants could be found in Ducoin et al. (2012b), Ducoin and Young (2011), Ducoin et al. (2010), and Huang et al. (2013).

\subsection{Solid model}

The NACA66 hydrofoil shown in Fig. 1 is modeled as a chordwise rigid, two degrees-of-freedom (2-DOF) system as shown in Fig. 2, which accounts for the spanwise bending $(h)$ and twist-angle $(\theta)$ displacements of the 3-D cantilever foil shown in Fig.1. These displacements are defined positive upwards and counterclockwise about the elastic axis, E.A., respectively. The hydrofoil is assumed to be initially aligned at an angle-of-attack of $\alpha_{o}=8^{\circ}$ with respect to the uniform inflow speed $U_{o}$

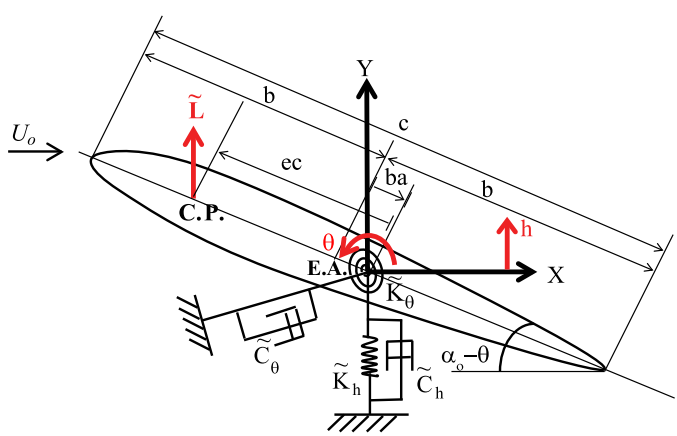

Fig. 2. The 2-DOF hydrofoil with bending and pitching flexibilities in a uniform inflow. 
along the $\mathbf{X}$ direction. In Fig. $2, b=c / 2$ is the half-chord; $a$ is the nondimensional distance (as a fraction of $b$ ) to the E.A. from the mid-chord position, which is positive towards the foil trailing edge; $e$ is the nondimensional distance (as a fraction of $c$ ) to the center of pressure (C.P., where the net lift force acts) from the E.A., which is positive towards the foil leading edge. $\left(x_{\theta}, y_{\theta}\right)$, which is not shown in Fig. 2, is the nondimensional distance (as fraction of $b$ ) along the $\mathbf{X}$ and $\mathbf{Y}$ directions, respectively, from the E.A. to the center of gravity (C.G.). The 3-D generalized hydrodynamic loads acting on the foil are denoted with $\tilde{D}$ for drag, $\tilde{L}$ for lift at the C.P., and $\tilde{T}$ for the moment about the E.A.; $\tilde{D}$, and $\tilde{L}$ are positive in the $\mathbf{X}, \mathbf{Y}$ directions, respectively, while $\tilde{T}$ is positive in the counterclockwise direction.

Following the classic aeroelasticity [see Bisplinghoff et al. (1955) and Fung (2008) for more details], the equations of motion of the 3-D rectangular wing with uniform cross-section are expressed in generalized coordinates. To do so, $h$ and $\theta$ are decomposed into time- and space-varying parts as

$$
\begin{aligned}
& h(z, t)=\bar{h}(t) f(z), \\
& \theta(z, t)=\bar{\theta}(t) g(z),
\end{aligned}
$$

where $f(z)$ and $g(z)$ are respectively the normalized bending and twisting shape functions, which are given for the current hydrofoil in Ducoin and Young (2013); they are both zero at the fixed end $(z=0)$ and unity at the free-end $(z=s)$ of the cantilevered hydrofoil, as shown in Fig. 3; $\bar{h}$ and $\bar{\theta}$ are the time-dependent components of $h$ and $\theta$, respectively.

Using these decompositions, and as derived in Appendix, for $\left(x_{\theta}, y_{\theta}\right)=(0,0)$, the equations of motion of the hydrofoil can be written as

$$
\begin{aligned}
& \tilde{m} \ddot{\bar{h}}+\tilde{C}_{h} \dot{\bar{h}}+\tilde{K}_{h} \bar{h}=\tilde{L}, \\
& \tilde{I}_{\theta} \ddot{\bar{\theta}}+\tilde{C}_{\theta} \dot{\bar{\theta}}+\tilde{K}_{\theta} \bar{\theta}=\tilde{T} .
\end{aligned}
$$

In Eqs. (8) and (9), $\tilde{m}$ is the 3-D generalized mass of the foil; $\tilde{I}_{\theta}$ is the 3-D generalized moment of inertia of the foil along its E.A.; $\tilde{K}_{h}$ and $\tilde{K}_{\theta}$ are respectively the spanwise bending and twisting stiffness values; and $\tilde{C}_{h}$ and $\tilde{C}_{\theta}$ are respectively the spanwise bending and twisting damping values. In Eqs. (8) and (9) the parameters with overhead tildes denote 'generalized' parameters, as they are derived from their 2-D equivalents, as shown in Appendix.

$\tilde{L}$ and $\tilde{T}$ are given in Eqs. (13) and (14) (through Eqs. (10) and (11)), and are only approximate; they are derived and discussed in Appendix. In Eqs. (10) and (11), $L^{\prime}$ and $T$ are the 2-D (per unit span) hydrodynamic lift and moment induced on the foil that are computed through the 2-D uRANS (fluid dynamics model) solver, and the integrations are along the closed 2-D foil surface $(A)$. Similarly, Eq. (12) gives the 2-D hydrodynamic drag force, D', acting on the hydrofoil. In Eqs. (10)-(12), i and $\mathbf{j}$ are unit vectors along the $\mathbf{X}$ and $\mathbf{Y}$ directions (shown in Fig. 2), $\mathbf{n}$ is an unit normal vector on the foil surface pointing towards the fluid, and $\mathbf{r}$ is a position vector from the E.A. to a point on the foil surface.

$$
\begin{aligned}
& L^{\prime}=\oint \mathbf{j} \cdot\left(-p \mathbf{I}+\mu\left(\nabla \mathbf{u}+\nabla \mathbf{u}^{T}\right)\right) \mathbf{n} d A, \\
& T^{\prime}=\oint \mathbf{r} \times\left(-p \mathbf{I}+\mu\left(\nabla \mathbf{u}+\nabla \mathbf{u}^{\mathrm{T}}\right)\right) \mathbf{n} d A, \\
& D^{\prime}=\oint \mathbf{i} \cdot\left(-p \mathbf{I}+\mu\left(\nabla \mathbf{u}+\nabla \mathbf{u}^{\mathrm{T}}\right)\right) \mathbf{n} d A, \\
& \tilde{L}=\int_{0}^{s} L^{\prime} f(z) d z \approx L^{\prime} s_{f f}, \\
& \tilde{T}=\int_{0}^{s} T^{\prime} g(z) d z \approx T^{\prime} s_{g g},
\end{aligned}
$$

with

$$
\begin{aligned}
& s_{f f}=\int_{0}^{s} f(z)^{2} d z, \\
& s_{g g}=\int_{0}^{s} g(z)^{2} d z .
\end{aligned}
$$

Next, Eq. (17) defines the nondimensional lift $\left(C_{L}\right)$, drag $\left(C_{D}\right)$, and moment $\left(C_{M}\right)$ coefficients about the foil E.A., respectively. Based on experimental measurements of Ducoin et al. (2012a) for a POM polyacetate foil and using the relations in Eqs. (A.6)-(A.11) (given in Appendix), the mass and mass moment of inertia, damping, spring constants, and natural frequencies used in the simulations are as given in Table 1.

$$
C_{L}=\frac{L^{\prime}}{(1 / 2) \rho_{l} U_{o}^{2} c}, \quad C_{D}=\frac{D^{\prime}}{(1 / 2) \rho_{l} U_{o}^{2} c}, \quad C_{M}=\frac{T^{\prime}}{(1 / 2) \rho_{l} U_{o}^{2} c^{2}} .
$$


Table 1

List of the geometric and dynamic parameters for the NACA66 hydrofoil used in the simulations.

\begin{tabular}{lll}
\hline Chord $(c=2 b)$ & $0.15 \mathrm{~m}$ & Mass $(\tilde{m})$ \\
Span $(s)$ & $0.191 \mathrm{~m}$ & Moment of inertia $\left(\tilde{I}_{\theta}\right)$ \\
Max. thickness & $0.018 \mathrm{~m}$ & Bending stiffness $\left(\tilde{K}_{h}\right)$ \\
$a$ & -0.0667 & Torsion stiffness $\left(\tilde{K}_{\theta}\right)$ \\
$x_{\theta}, y_{\theta}$ & $-0.0112,0.0315$ & Damping factor for bending $\left(\zeta_{h}\right)$ \\
2-D Mass $\left(m^{\prime}\right)$ & $2.94 \mathrm{~kg} / \mathrm{m}$ & $095 \mathrm{~N} / \mathrm{m}$ \\
2-D Moment of inertia $\left(I_{\theta}^{\prime}\right)$ & $3.70 \times 10^{-3} \mathrm{~kg} \mathrm{~m}$ & Damping factor for torsion $\left(\zeta_{\theta}\right)$ \\
Bending natural frequency in air $\left(f_{h}^{a}\right)$ & $114 \mathrm{~Hz}$ & Damping value for bending $\left(\tilde{C}_{h}\right)$ \\
Torsion natural frequency in air $\left(f_{\theta}^{a}\right)$ & $361 \mathrm{~Hz}$ & Damping value for torsion $\left(\tilde{C}_{\theta}\right)$ \\
\hline
\end{tabular}

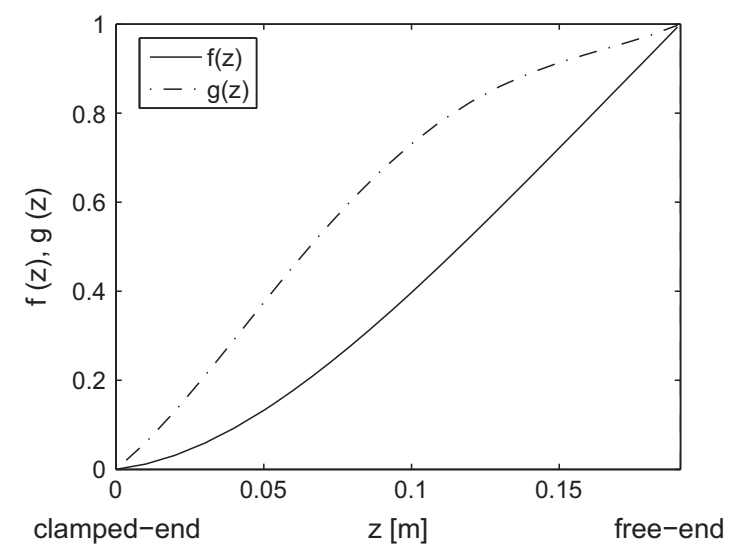

Fig. 3. The normalized shape functions $f(z)$ and $g(z)$ used in Eqs. (6) and (7).

The coupled flexible hydrofoil and cavitating fluid dynamics simulation results shown next used $\left(x_{\theta}, y_{\theta}\right)=(0,0)$ after verifying that the simulations with $\left(x_{\theta}, y_{\theta}\right)=(-0.0112,0.0315)$ yielded practically the same results. Note that if there is no fluid load, the bending $(h)$ and twist $(\theta)$ deformations would be uncoupled. However, for the case of the flexible hydrofoil in water, the fluid-induced coupling dominates compared to the small geometric coupling associated with the small nonzero $\left(x_{\theta}, y_{\theta}\right)$, and simulations have been performed to confirm that there is negligible difference between the solutions obtained using $\left(x_{\theta}, y_{\theta}\right)=(0,0)$ and $(-0.0112,0.0315)$.

\subsection{Fluid-structure interaction (FSI) model}

The current simulations use the Loose Hybrid Coupled (LHC) method as the fluid-structure interaction (FSI) model, which was introduced in Young et al. (2012). The LHC method is a partitioned FSI algorithm, as it couples the solutions of the two separate solid and fluid solvers. The LHC method embeds the potential flow solution in the modified equations of motion to stably and efficiently couple the viscous flow and flexible solid models; it was shown in Young et al. (2012) to be far superior in modeling lightweight solids in incompressible, dense fluid flows compared to the conventional loosely coupled and tightly coupled schemes. The LHC method has been validated for a range of hydroelastic problems for subcavitating flows in Chae et al. (2013). As discussed in Forster et al. (2007) and Young et al. (2012), numerical instability is a particular concern for the FSI modeling of lightweight solids in dense fluid flows, because the fluid forces may be in the same order of magnitude with the solid forces. The artificial added mass instability is caused by the lag in exchange of interfacial displacements and forces between the fluid and solid solvers in partitioned algorithms, which depend on each other's solution, especially for strongly coupled FSI problems.

For the 2-DOF NACA66 hydrofoil of interest and in uniform inflow, the coupled equations of motion (EOM) are shown in Eq. (18), where $i$ is the time-step index. Since this approach does not iterate within each time-step, it is called the Loosely Hybrid Coupled method. The term $\tilde{F}_{\text {fluid }}^{T}$ in Eq. (18) is the 'generalized' potential flow estimate of the fluid forces and is present at both the left- and right-hand sides of the EOM: the term on the left-hand side is treated implicitly and the term on the right-hand side is treated explicitly. Observe that for very small time-step sizes, the terms $\tilde{F}_{\text {fluid }}^{T}$ will drop out of the EOM, while the effect of the fluid loading on the hydrofoil is represented by $\tilde{L}$ and $\tilde{T}$, which are obtained from the viscous 
flow solver. The sole presence of $\tilde{F}_{\text {fluid }}^{T}$ in the EOM is to make the EOM 'effectively implicit' and to ease the potential virtual added mass numerical stability problems.

$$
\underline{\tilde{M}}\left\{\begin{array}{l}
\ddot{\bar{h}} \\
\ddot{\bar{\theta}}
\end{array}\right\}^{i+1}+\underline{\tilde{C}}\left\{\begin{array}{l}
\dot{\bar{h}} \\
\dot{\bar{\theta}}
\end{array}\right\}^{i+1}+\underline{\tilde{K}}\left\{\begin{array}{l}
\bar{h} \\
\bar{\theta}
\end{array}\right\}^{i+1}-\left(\tilde{F}_{\text {fluid }}^{T}\right)^{i+1}=-\left(\tilde{F}_{\text {fluid }}^{T}\right)^{i}+\left\{\begin{array}{c}
\tilde{L} \\
\tilde{T}
\end{array}\right\}^{i},
$$

with

$$
\left.\left.\left.\underline{\tilde{M}}=\begin{array}{cc}
\tilde{m} & 0 \\
0 & \tilde{I}_{\theta}
\end{array}\right), \quad \tilde{\underline{C}}=\begin{array}{cc}
\tilde{C}_{h} & 0 \\
0 & \tilde{C}_{\theta}
\end{array}\right), \quad \underline{\tilde{K}}=\begin{array}{cc}
\tilde{K}_{h} & 0 \\
0 & \tilde{K}_{\theta}
\end{array}\right),
$$

and

$$
\left(\tilde{F}_{\text {fluid }}^{T}\right)^{i}=-\underline{\tilde{M}}^{T}\left\{\begin{array}{l}
\ddot{\bar{h}} \\
\ddot{\bar{\theta}}
\end{array}\right\}^{i}-\underline{\tilde{C}}^{T}\left\{\begin{array}{l}
\dot{\bar{h}} \\
\dot{\bar{\theta}}
\end{array}\right\}^{i}-\underline{\tilde{K}}^{T}\left\{\begin{array}{l}
\bar{h} \\
\bar{\theta}
\end{array}\right\}^{i}
$$

is the potential flow fluid forcing with

$$
\begin{aligned}
& \underline{\tilde{M}}^{T}=\left(\begin{array}{cc}
\pi \rho_{l} b^{2} s_{f f} & -\pi \rho_{l} a b^{3} s_{f g} \\
-\pi \rho_{l} a b^{3} s_{f g} & \pi \rho_{l} b^{4}\left(\frac{1}{8}+a^{2}\right) s_{g g}
\end{array}\right), \\
& \underline{\tilde{C}}^{T}=\pi \rho_{l} U_{o} b^{2}\left(\begin{array}{cc}
\frac{2}{b} \Theta(k) S_{f f} & (1+(1-2 a) \Theta(k)) s_{f g} \\
-(1+2 a) \Theta(k) S_{f g} & b\left(a-\frac{1}{2}\right)(-1+(1+2 a) \Theta(k)) S_{g g}
\end{array}\right), \\
& \left.\underline{\tilde{K}}^{T}=\pi \rho_{l} U_{o}^{2} b \Theta(k) \quad \begin{array}{ccc}
0 & 2 s_{f g} \\
0 & -b(1+2 a)) s_{g g}
\end{array}\right) \quad \text { with } \Theta(k)=\frac{H_{1}^{2}(k)}{H_{1}^{2}(k)+\sqrt{-1} H_{0}^{2}(k)} .
\end{aligned}
$$

In Eq. (18)

$$
s_{f g}=\int_{0}^{s} f(z) g(z) d z
$$

$H_{o}^{2}$ and $H_{1}^{2}$ are Hankel functions (which are linear combinations of Bessel functions of the 3rd kind); $\tilde{L}$ and $\tilde{T}$ are found from Eqs. (13) and (14); and $k=\omega b / U_{o}$ is the reduced frequency where $\omega$ is the primary estimated vibration frequency of the hydrofoil. $\underline{\tilde{M}}, \underline{\tilde{C}}$, and $\underline{\tilde{K}}$ in Eq. (18) are the 'generalized' structural mass, damping and stiffness matrices, while $\underline{\tilde{M}}^{T}, \underline{\tilde{C}}^{T}$, and $\underline{\tilde{K}}^{T}$ are their potential flow counterparts in $\tilde{F}_{\text {fluid }}^{T}$, and are calculated in this work following Theodorsen's approach described in Sears (1941) and Theodorsen (1935). If Eq. (18) is scaled by using $b$ as the length scale, $\rho_{l} b^{3}$ as the mass scale, and $2 \pi / \omega$ as the time scale, it could be shown that the non-dimensionalized $\underline{\tilde{C}}^{T}$ is proportional to $2 \pi / k, \tilde{\tilde{K}}^{T}$ is proportional to $(2 \pi / k)^{2}$, and $\underline{\tilde{M}}^{T}$ does depend on $k$. So for typical vibration frequencies between 0.1 and $10 \mathrm{~Hz}$, inflow fluid speeds between 1 and $20 \mathrm{~m} / \mathrm{s}$, and chord lengths between 0.1 and $1 \mathrm{~m}$, the fluid damping and stiffness terms will remain important as $2 \pi / k$ is typically less than 1 , and the terms will become important as $k$ decreases with increases in $U_{o}$. Note that Theodorsen's estimate of $\tilde{F}_{\text {fluid }}^{T}$ is only valid for thin foils undergoing small amplitude harmonic oscillations with low angles-of-attack in potential flow conditions. Eq. (18) is discretized with Crank-Nicholson's approach.

Using the potential theory, the bending $\left(f_{h}^{f W}\right)$ and torsional $\left(f_{\theta}^{f W}\right)$ frequencies of the hydrofoil in water are as given in Eqs. (20) and (21); for the current foil geometry and water properties, they are respectively found as $43 \mathrm{~Hz}$ and $171 \mathrm{~Hz}$. Note that as stated in Ducoin et al. (2012a), the experimentally measured $f_{h}^{f W}$ and $f_{\theta}^{F W}$ of this foil in water were also $43 \mathrm{~Hz}$ and $171 \mathrm{~Hz}$, respectively.

$$
\begin{aligned}
f_{h}^{F W} & =\frac{1}{2 \pi} \sqrt{\frac{\tilde{K}_{h}}{\tilde{m}+\pi \rho_{l} b^{2} s_{f f}}}, \\
f_{\theta}^{F W} & \approx \frac{1}{2 \pi} \sqrt{\frac{\tilde{K}_{\theta}}{\tilde{I}_{\theta}+\pi \rho_{l} b^{4}\left((1 / 8)+a^{2}\right) s_{g g}}} .
\end{aligned}
$$

\subsection{Physical and numerical set-up}

The numerical domain of the computational fluid dynamics (CFD) solver is as shown in Fig. 4a. The numerical domain is $15 \mathrm{c}$ wide and $1.28 \mathrm{c}$ tall; the undeformed foil's E.A. is at the domain mid-height, the foil leading edge is at $4.5 \mathrm{c}$ from the inlet, and the foil trailing edge is at $9.5 \mathrm{c}$ from the outlet. All the simulations used $\mathrm{Re}=750000$ and $\alpha_{0}=8^{\circ}-$ initial angle of attack of the foil. The boundary conditions are: no-slip and no-penetration conditions at the foil interface (i.e. no relative motion between the fluid particles and the foil at the surface of the deforming foil), uniform water inflow at a speed of $U_{o}=5 \mathrm{~m} / \mathrm{s}$ 

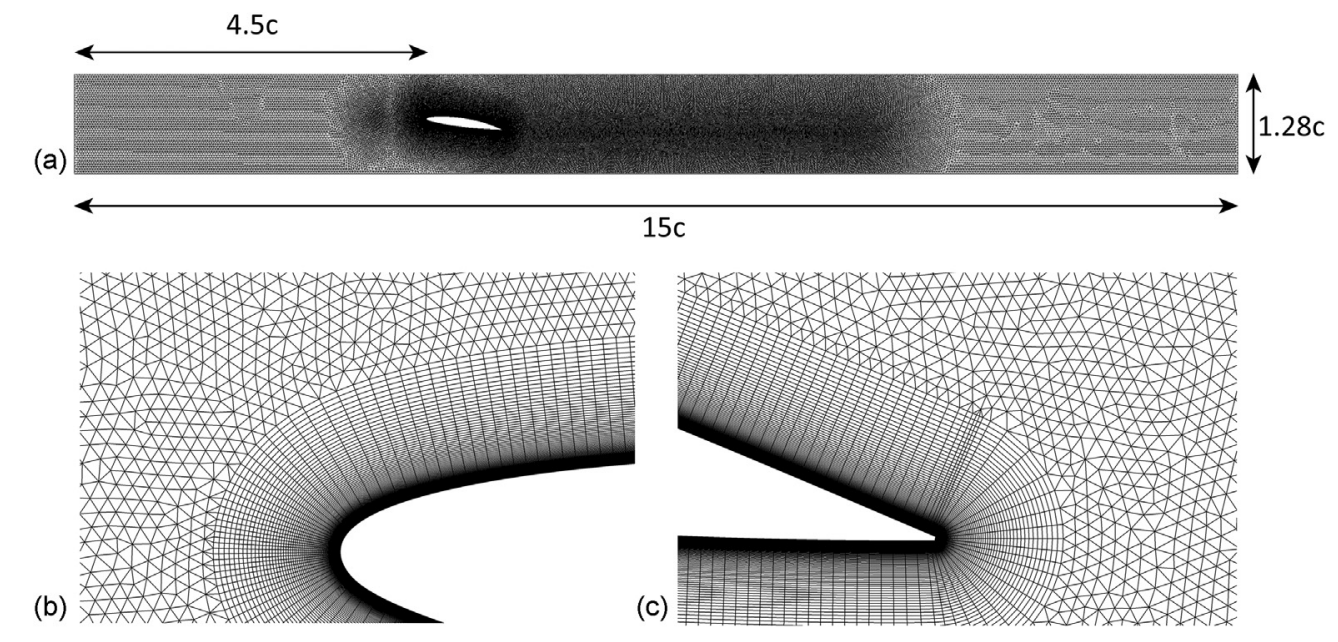

Fig. 4. The mesh used to perform the CFD solution. (a) shows the full-extend of the numerical domain, (b) is a close-up near the foil leading edge, and (c) is a close-up near the foil trailing edge.

with 2.95\% turbulence intensity, prescribed static pressure $p_{o}$ at the outlet according to the cavitation number $\sigma$ - defined in Eq. (22) - and symmetry $(v=0, \partial u / \partial y=0)$ conditions at the top and bottom boundaries. In the simulations, $p_{v}$ is taken as $3169 \mathrm{~Pa}$ for pure water at $25^{\circ} \mathrm{C}$. Following the observations stated in Ducoin and Young (2013), the flow is assumed to be fully-turbulent on this foil geometry at $\alpha_{o}=8^{\circ}$ and Re. The initial conditions of the simulations are the steady-state solutions of the 'fully-wetted' (FW) simulations.

$$
\sigma=\frac{p_{o}-p_{v}}{(1 / 2) \rho_{l} U_{o}^{2}} \text {. }
$$

The mesh used for the CFD analysis is shown in Fig. 4, which was constructed with ANSYS CFX-Mesh (version 12.1). The mesh consists of unstructured triangular elements everywhere, but near the hydrofoil, where a structured boundary-layer mesh is used as illustrated in Fig. 4b and 4c. The mesh has 194000 elements, and the smallest element near the hydrofoil satisfied an estimated $y^{+}=\rho_{l} u_{\tau} y / \mu_{l}$ value of 0.5 , where $u_{\tau}$ is the estimated friction velocity, and $y$ is the thickness of the first cell adjacent to the foil surface. At the every time-step, once the new foil position is computed from the solid solver [i.e. Eq. (18)], the fluid mesh is deformed to conform to the new foil position. More information on the mesh deformation is given in Section 1.2.2 in ANSYS (2011). Briefly speaking, the mesh is treated as an elastic solid with variable stiffness and it is constrained to conform to the moving hydrofoil geometry, as well as the other domain boundaries. The mesh stiffness is proportional to the inverse of the mesh element size, and the mesh deformation is computed by solving $\nabla \cdot\left(k_{\text {mesh }} \nabla \delta\right)=0$ with the appropriate boundary conditions, where $k_{\text {mesh }}$ is the variable mesh stiffness and $\delta$ is the mesh deformation. Since the mesh elements are finer near the hydrofoil, the mesh elements move with the hydrofoil without much of a distortion. However, the relatively larger mesh elements far away from the hydrofoil get distorted, as the mesh at the flow inlet and outlet is assumed to be stationary, while the mesh could compress or stretch towards the top and bottom domain boundaries. Hence, care was taken to ensure that the mesh and time-step size are fine enough to limit mesh distortion issues after each structural calculation.

The time-step size for both the fluid and solid solvers was selected to be $\Delta t=4 \times 10^{-4} \mathrm{~s}$, which corresponded to a root mean square CFL number about 2 (computed over all the mesh elements in the grid). For both the fully-wetted and cavitating flow cases over a flexible foil with $\sigma=1.4$, the current mesh and time-step size were shown to provide converged solutions in Akcabay et al. (2012). Specifically, the deformations and hydrodynamic lift and moment coefficients were less than $1 \%$ (and $C_{D}$ is less than $5 \%$ ) different by doubling the grid size and by halving the time-step size for the fully-wetted flows, while the frequency spectrum of $C_{L}$ was shown to be insensitive to grid and time-step size for cavitating flows with $\sigma=1.4$.

The computations were run on a cluster at the Center of Advanced Computing (CAC) at the University of Michigan with dual socket Intel Nehalem/I7 64-bit nodes (12 total cores per node), while the nodes were connected through a $40 \mathrm{Gbps}$ Infiniband network. Most of the simulation results were conducted by partitioning the simulation on 8 cores, and it took about 4 days to obtain results for the highly unsteady case with $\sigma=1.4$; the run times were shorter for the other cases with more regular cavity shedding patterns.

\section{Results}

For all the cases presented in this work, the flow conditions and physical parameters are $\operatorname{Re}=750000\left(=\rho_{l} U_{o} c / \mu_{l}\right.$, Reynolds number), $U_{o}=5 \mathrm{~m} / \mathrm{s}$ (with $2.95 \%$ turbulence intensity), $\rho_{l}=997 \mathrm{~kg} / \mathrm{m}^{3}, \rho_{v}=0.02308 \mathrm{~kg} / \mathrm{m}^{3}, \mu_{l}=8.9 \times 10^{-4} \mathrm{~kg} /(\mathrm{m} \mathrm{s})$, $\mu_{v}=9.8626 \times 10^{-6} \mathrm{~kg} /(\mathrm{m} \mathrm{s}), p_{v}=3169 \mathrm{~Pa}$, and $\alpha_{\mathrm{o}}=8^{\circ}$. 


\subsection{Fully-wetted response}

To validate the simulation, results are first shown for rigid and flexible hydrofoils in fully-wetted (FW, sub-cavitating) flow. The experimentally measured $C_{L}, C_{D}$, and $C_{M}$ for the rigid hydrofoil (Leroux et al., 2004) are compared with the numerically predicted values for both the rigid and the flexible hydrofoils in Table 2 . It should be noted that the experimental measurements from the flexible hydrofoil (Ducoin et al., 2012a) do not include the hydrodynamic load coefficients or pressure distributions. However, Table 2 includes the predicted and measured $h$ and $\theta$ from (Ducoin et al., 2012a). Additionally, Fig. 5 compares the predicted and measured pressure coefficients, $C_{p}$ (as defined in Eq. (23), where $p_{o}$ is the absolute tunnel pressure) along the hydrofoil surfaces. In Fig. $5, x / c=0$ is the foil leading edge (LE) position and $x / c=1$ is the trailing edge (TE) position.

$$
C_{p}=\frac{p-p_{o}}{(1 / 2) \rho_{l} U_{o}^{2}}
$$

In Table 2, the numerical lift coefficients $\left(C_{L}\right)$ are higher, and the numerical drag coefficients $\left(C_{D}\right)$ are lower, than the experimentally measured values for the rigid hydrofoil; this is because the present computations are in 2-D, which ignores 3 -D effects, including contributions from the induced drag due to the finite aspect ratio $(s / c=1.27)$, and the energy dissipation through the gap and tip vortices, as well as the wall boundary layer effects at the foil root - these effects are detailed in Harwood and Young (2014). Harwood et al. (2012) showed for the same hydrofoil that the sectional lift coefficient and pressure distributions are mostly uniform throughout the foil span except very near the foil tip and root. The reason why the measured $C_{L}$ is only slightly lower than the predicted values while the measured $C_{D}$ is much higher, is because while $C_{L}$ is primarily affected by pressure effects, while $C_{D}$ is affected by 3-D induced drag and losses through the tip vortex and wall boundary layers.

The differences between the predicted and measured deformations in Table 2 are due to (i) the approximations given in Eqs. (13) and (14), and (ii) small variations in the $f$ and $g$ shape functions (used in Eqs. (8) and (9) and plotted in Fig. 3) with effective angles of attack. The Appendix includes an error analysis for the approximations given in Eqs. (13) and (14). Note that Eqs. (13) and (14) construct the 3-D generalized lift force and moment from the predicted 2-D values evaluated from the 2-D CFD solver; these 3-D generalized lift forces and moments are then used in the simulations to calculate the hydrofoil deformations and dynamic response with the generalized 3-D stiffness values. As stated in the Appendix and as will be verified next in Section 4.2, while the approximations of Eqs. (13) and (14) can lead to some errors for predicting the hydrofoil displacements, they are accurate in predicting the frequency response of the hydrofoil dynamics. Since the primary results and interpretations given further in this paper are based on the frequency response of the flexible hydrofoil in cavitating flows, the current formulation is regarded sufficient.

Table 2

Hydrodynamic load coefficients on the hydrofoil at $\operatorname{Re}=750000, \alpha_{o}=8^{\circ}$ for non-cavitating flows.

\begin{tabular}{lllll}
\hline & $C_{L}$ & $C_{D}$ & $C_{M}$ (along the E.A.) & h/c \\
\hline Experiment, rigid & 1.065 & 0.048 & N/A & - \\
Experiment, flexible & N/A & N/A & N/A & - \\
Computation, rigid & 1.19 & 0.022 & -0.204 & -0.024 \\
Computation, flexible & 1.22 & 0.022 & -0.210 & - \\
\hline
\end{tabular}

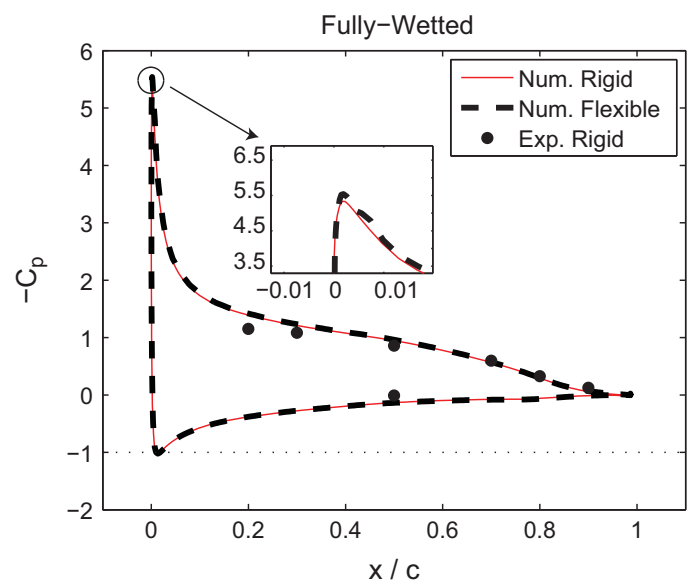

Fig. 5. Comparisons of the measured and predicted pressure coefficient, $C_{p}$, along the hydrofoil surface for the rigid and the flexible hydrofoil at $\operatorname{Re}=750000, \alpha_{o}=8^{\circ}$. 
3-D extensions of the LHC method are underway, and will be presented in future publications. It should be noted that fully 3-D FSI simulations with transient cavitation are computationally intensive and requires a very careful effort to generate and control the deformations of both the fluid and solid mesh details.

As shown in Fig. 5, in general, there is a good agreement between the predicted and measured pressure distributions for the rigid hydrofoil. There are some small differences between the flexible and rigid numerical results, because the twisting flexibility allowed the flexible foil to attain higher effective angle-of-attack, $\alpha_{e f f}$. Note that the center of pressure of this foil is on the LE side (relative to the E.A.) of the hydrofoil and hence the fluid lift forces induce a clockwise moment about the E.A., resulting in higher $\alpha_{\text {eff }}$ and lift and drag force, as evidenced in Table 2 and discussed in Ducoin and Young (2013).

\subsection{Unsteady sheet/cloud cavitation}

This part examines the dynamic response of the rigid and flexible hydrofoils under unsteady sheet/cloud cavitating flows at $\operatorname{Re}=750000$ and $\alpha_{o}=8^{\circ}$. First, Fig. 6 shows the effect of $\sigma$ on the frequency spectrum of the bending displacements $(h)$ for the flexible foil for both FW and cavitating flow conditions. The experimentally measured results from Ducoin et al. (2012a) are also included in the same plots, where the highest spectral magnitudes of the experimental and numerical results (vertical axis) are scaled to match each other, so that they can be compared at ease.

The measured frequency spectrum for the FW, $\sigma=2.6$, and 2.0 cases were calculated through using the measured time and spatial average of the hydrofoil vibration on a grid of 32 individual points on the 3-D foil surface [see Ducoin et al. (2012a) for more details]. It is due to this spatial averaging that the unscaled spectral magnitudes of the numerical results were higher than the experimental measurements, for the cases with $\sigma=2.6$ and 2.0. For the case of $\sigma=1.4$, corresponding to strong unsteady cavitation, it was quite difficult to get an accurate measurement of the vibration spectrum by the laser vibrometer due to high level of surrounding vibrations; however, it was possible to get the structural response by analyzing images of the free tip section. For the case with $\sigma=1.4$, the unscaled predicted structural displacements, and hence the spectral magnitudes, were relatively lower than the measured values (within the same proportions as given in Table 2) due to the reasons given in Section 4.1 and in Appendix A.

(a)

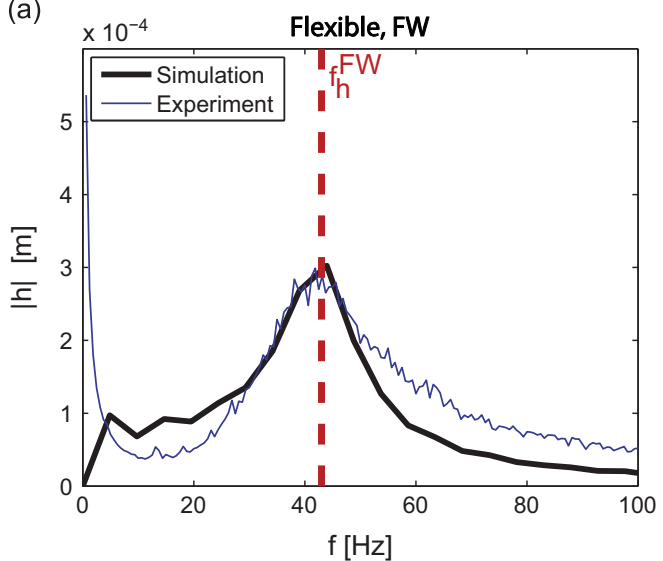

(c)

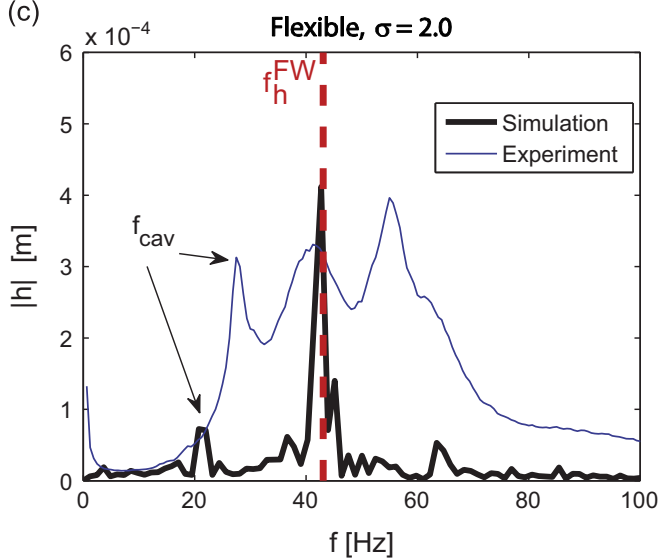

(b)

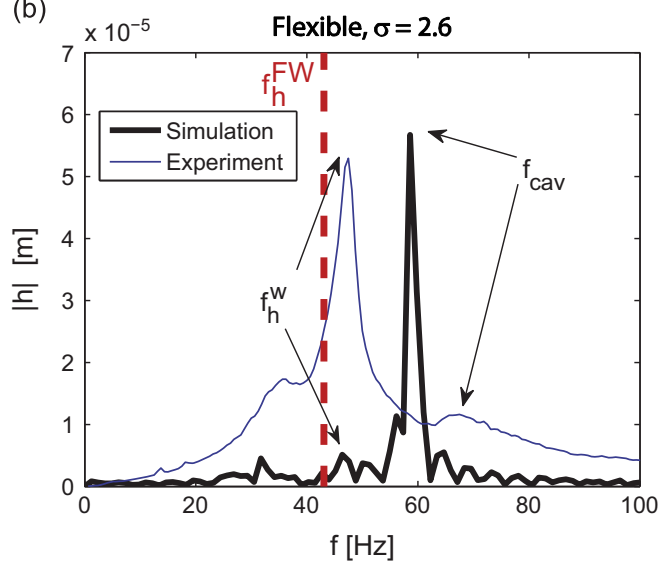

(d)

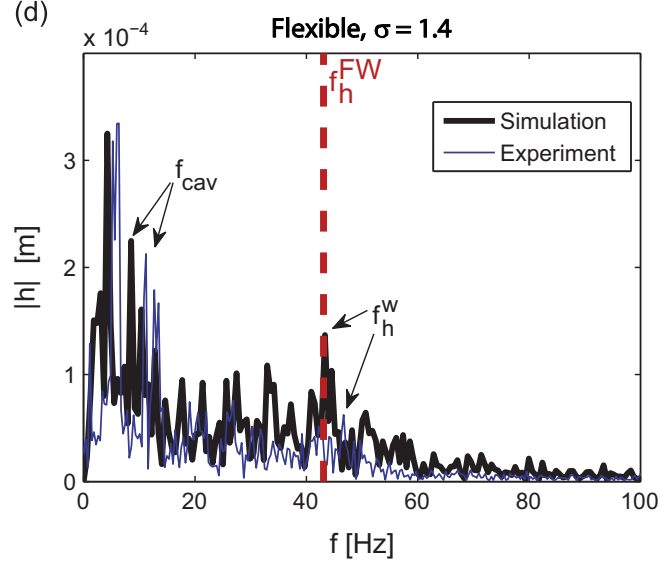

Fig. 6. The effect of $\sigma$ on the frequency spectrum of $h$. (a) Fully-wetted (FW) case, (b) $\sigma=2.6$, (c) $\sigma=2.0$, (d) $\sigma=1.4$. Numerical results: solid dark lines; experimental measurements (Ducoin et al., 2012a; Benaouicha et al., 2009): solid light lines. The vertical dashed lines are the theoretical wetted natural bending frequencies $f_{h}^{W}$ based on Eq. (20). 
In Fig. 6 there is a general agreement between the numerically and experimentally determined frequency response of the hydrofoil bending displacement for different $\sigma$, while there are some differences with the relative strengths of the dominant spectral content. Table 3 lists the cavity shedding, $f_{\text {cav }}$, and wetted bending natural frequencies, $f_{h}^{w}$ observed in Fig. 6 . Also shown in Fig. 6 and Table 3 are the predicted fully-wetted (FW) bending natural frequency, based on Eq. (20).

Fig. 6 shows that the predicted $f_{h}^{w}$ is the same as the measured value for the FW case. At $\sigma=2.6$ for the flexible foil, the simulations predicted a single powerful frequency peak at $59 \mathrm{~Hz}$, while the experimental results showed a powerful spike at $47.5 \mathrm{~Hz}$, which is near the wetted bending natural frequency suggesting lock-in, and a secondary spike at $68 \mathrm{~Hz}$. The result in Fig. $6 \mathrm{c}$ for $\sigma=2.0$ shows similar frequency content for predicted and measured response. The measured frequency peaks are at $27.5 \mathrm{~Hz}, 41.3 \mathrm{~Hz}$, and $55 \mathrm{~Hz}$, while the predicted frequency peaks are at $21 \mathrm{~Hz}, 43 \mathrm{~Hz}$, and $63 \mathrm{~Hz}$. In Fig. $6 \mathrm{~d}$, at $\sigma=1.4$, the numerical results predicted the cavity shedding frequency to be about $8.5 \mathrm{~Hz}$, while the measured frequency was $11 \mathrm{~Hz}$. At $\sigma=1.4$, both the numerical and experimental results showed a powerful frequency peak at a frequency nearly at half of the cavity shedding frequency: near $4.5 \mathrm{~Hz}$ for the numerical prediction, and $6 \mathrm{~Hz}$ for the flexible experimental case. Fig. $6 \mathrm{~d}$ also reveals that at $\sigma=1.4$, the wetted bending natural frequency of the flexible hydrofoil $\left(f_{h}^{N}\right)$ is also exited, in both experimental measurements and numerical predictions.

Table 3

Comparisons of the experimentally measured [Ducoin et al. (2012a) for $\sigma=2.6,2.0$, Benaouicha et al. (2009) for $\sigma=1.4$ ] and numerically derived cavity shedding $\left(f_{\text {cav }}\right)$ and modified bending natural frequencies $\left(f_{h}^{w}\right)$ of the flexible hydrofoil.

\begin{tabular}{|c|c|c|c|c|c|}
\hline & \multicolumn{2}{|c|}{$f_{\text {cav }}[\mathrm{Hz}]$} & \multicolumn{3}{|c|}{$f_{h}^{w}[\mathrm{~Hz}]$} \\
\hline & Num. & Exp. & Num. & Exp. & FW theory \\
\hline Fully-wetted & - & - & 44 & 43 & 43 \\
\hline$\sigma=2.6$ & 59 & 68 & 46 & 47.5 & 43 \\
\hline$\sigma=2.0$ & 21 & 27.5 & 43 & 41 & 43 \\
\hline$\sigma=1.4$ & 8.5 & 11 & 43 & 47 & 43 \\
\hline
\end{tabular}

(a)

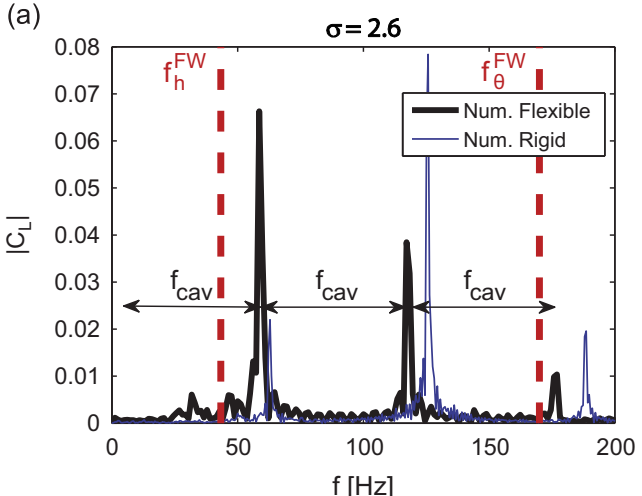

(c)

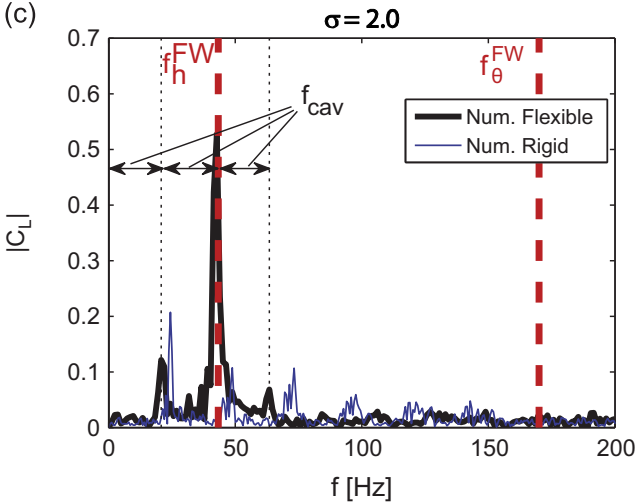

(b)

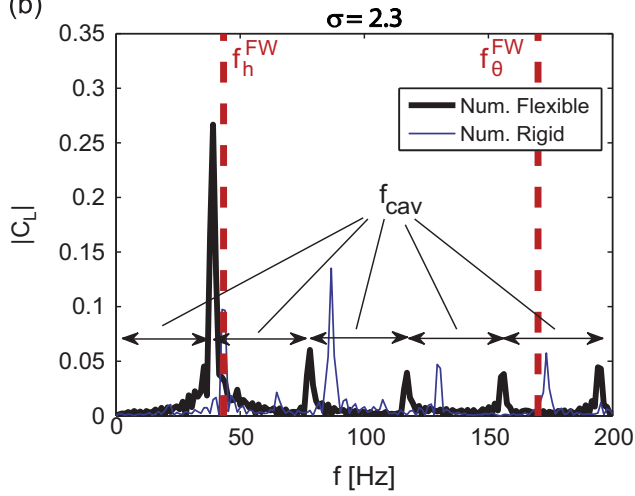

(d)

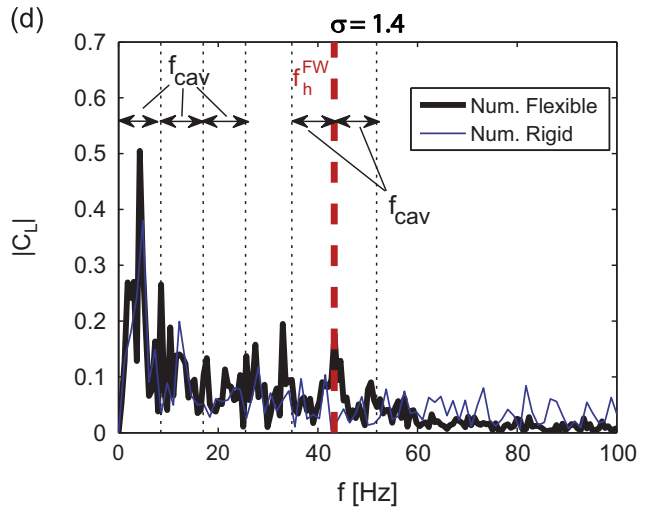

Fig. 7. The effect of $\sigma$ on the predicted frequency spectrum of $C_{L}$ for the rigid and flexible hydrofoils: (a) $\sigma=2.6$, (b) $\sigma=2.3$, (c) $\sigma=2.0$, (d) $\sigma=1.4$. The red vertical dashed lines are the theoretical wetted natural frequencies based on Eqs. (20) and (21). (For interpretation of the references to color in this figure legend, the reader is referred to the web version of this article.) 
Fig. 7 compares the predicted frequency spectrums of $C_{L}$ for both the flexible and rigid hydrofoil. Fig. 7 shows that the flexible hydrofoil has a consistent frequency peak near its theoretical wetted natural frequency of $f_{h}^{F W}=43 \mathrm{~Hz}$ for all the four cavitation numbers considered there (although these peaks are not always the strongest excitation). This is not the case for the rigid hydrofoil as it lacks structural dynamics. Note also that the spectrums of $C_{L}$ and $h$ in Figs. 6 and 7 are similar for the flexible hydrofoil.

Fig. 8 shows the spectral content of the predicted time-history of the twisting displacements $\theta$, of the flexible hydrofoil, along with the experimentally measured wetted bending $\left(f_{h}^{w, \exp }\right)$ and twisting $\left(f_{\theta}^{w,}{ }^{\text {exp }}\right)$ natural frequencies. Similar to the results for $h$, these plots show the wetted natural frequency of the twisting mode $\left(f_{\theta}^{w}\right)$ is mostly excited for the flexible hydrofoil in cavitational flow. Note that for the $\sigma=2.6$ case in Fig. 8a, the excited frequencies are at $f_{\theta}^{w} / 3,2 f_{\theta}^{w} / 3$, and $f_{\theta}^{w}$.

The effect of the cavitation number $\sigma$ on the predicted frequency content of the hydroelastic response of the rigid and flexible hydrofoils is further analyzed in Figs. 9 and 10. Fig. 10 shows the various experimental data reported in Kawakami et al. (2008), as well as the predicted and measured primary cavity shedding frequencies for the current rigid and flexible NACA66 hydrofoil. In Fig. 10, the effective angle-of-attack $\alpha_{\text {eff }}$ is defined as

$$
\alpha_{e f f}=\alpha_{o}-\alpha_{L o}-\theta
$$

where $\alpha_{L o}=-2.35^{\circ}$ is the angle-of-attack at which the lift force is zero, for the current NACA66 hydrofoil with camber. It should be noted that $\theta$ is defined positive counterclockwise, as shown in Fig. 2 . For all the cases shown in this paper, $\theta<0$, i.e. the flexible hydrofoil undergoes a clockwise rotation, because the center of pressure is ahead of the elastic axis, which leads to a higher $\alpha_{\text {eff }}$.

Figs. 9 and 10 show that, in general, the cavity shedding frequencies increase with $\sigma$. This is because as $\sigma$ decreases, the cavity would increase in length, and hence would require more time to evolve between the subsequent cavitational cycles. However, note in Fig. 9 that the predicted behavior is different for the rigid and flexible hydrofoils (as was also evidenced in Fig. 7): the cavity shedding frequencies of the flexible hydrofoil are focused - locked - on to the sub-harmonics of the hydrofoil's wetted natural frequencies $\left(f_{h}^{F W} / n, f_{\theta}^{F W} / n\right.$, with $\left.n=1,2,3, \ldots\right)$. This phenomenon is qualitatively similar to the cases reported in Ausoni et al. (2007) and Kato et al. (2006), in which the flow frequencies were locked-in to the natural or external excitation frequencies of the hydrofoil (Kato et al. (2006) referred sub-harmonic lock-in as 'quasi lock-in'). Fig. 10

(a)

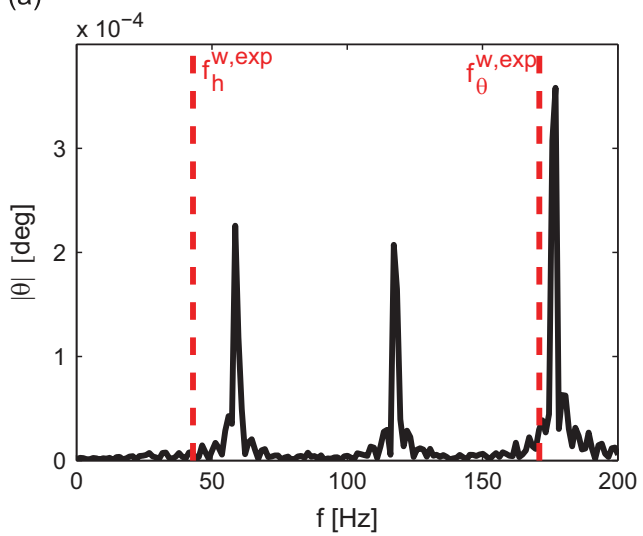

(b)

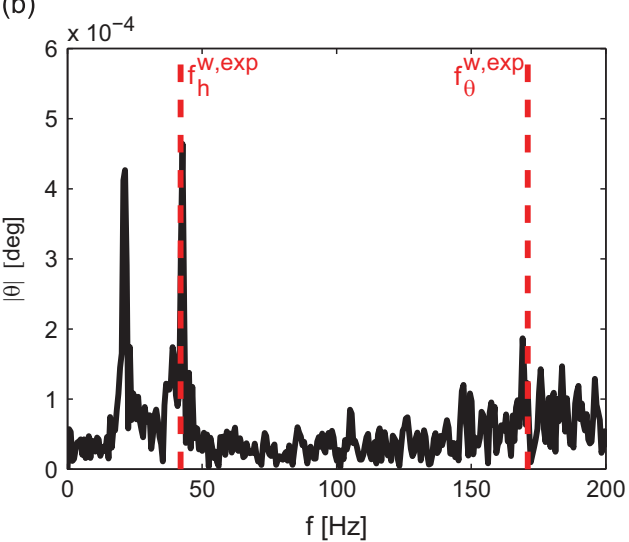

(c)

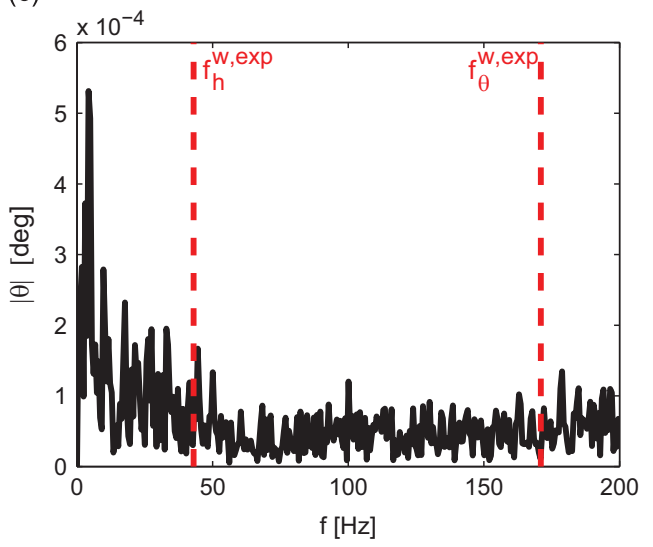

Fig. 8. Frequency spectrum of the numerically measured $\theta$ data for the flexible hydrofoil at $\sigma=2.6$ (a), $\sigma=2.0$ (b), and $\sigma=1.4$ (c). The vertical dashed lines are the experimentally measured wetted natural frequencies. 
shows a good general agreement between the predicted reduced cavity shedding frequencies and previous expeirmental measurements for different hydrodoils. Moreover, as will be discussed next in Section 4.3, cavity shedding effectively modulates the system through introducing additional frequency peaks that are spread through the sub-harmonics.

The influence of $\sigma$ on the predicted mean $C_{L}, h$, and $\theta$ are given in Fig. 11, along with the measured $C_{L}, h$, and $\theta$ values for limited cases available. As shown in Fig. 11a and as discussed in Section 4.1, the mean $C_{L}\left(\bar{C}_{L}\right)$ in FW condition for the rigid foil is higher than the measured values because the 3-D hydrodynamic effects were not considered in the current model. Both FW and cavitating results show that $\bar{C}_{L}$ is higher for the flexible hydrofoil than the rigid foil due to the increased effective angle of attack caused by the clockwise twisting motion, which is consistent with the $\theta$ values reported in Fig. 11b. As shown in Fig. 11b, the computed bending deformations are smaller, but they follow the same trend as the measured values, which is probably due to the same reasons as noted in Section 4.1 for the fully-wetted hydrofoil response at steady state. Fig. 12 shows that both the predicted and the measured maximum attached cavity length, $l_{c, \max } / c$, increase with decreasing $\sigma$, and good agreement was observed between the predicted and measures values. In general, the mean $C_{L}, h$, and $\theta$ decrease with decreasing $\sigma$, except for a local maxima near $\sigma=2.0$ due to partial leading-edge cavitation. The standard deviations of $C_{L}$ and $h$ (not shown here) were observed to rapidly increase with decreasing $\sigma$, due to the increased unsteadiness of the cavity. In general, once $l_{c, \max } / c$ exceeds 0.5 , the cavity becomes increasingly unstable, and will undergo partial or complete shedding. The lift coefficient decreases once the sheet/cloud cavity comes close to or exceeds the foil trailing edge (TE) for $\sigma<2$; this is because once the cavity reaches the foil TE, the suction side pressure is reduced to $p_{v}$, and the pressure side pressure is also forced to decrease significantly, since the pressure at both sides of the foil TE must be equal to $p_{v}$ due to the supercavity. However, if the cavity does not come close to the foil TE, the pressure profile at the pressure side remains high and the presence of the partial cavity at the suction side leads to a high mean $C_{L}$ value as evidenced by the presence of a local peak near $\sigma=2$. The presence of cavity tends to increase the drag coefficient, and hence will lead to a lower lift to drag ratio. The twist angle's dependence on $\sigma$ is similar to the dependencies of $h$ and $C_{L}$ on $\sigma$; this is expected as the fluid-induced moment on the foil depends directly on $C_{L}$. However, the behavior is non-linear because as $\sigma$ decreases, the center of pressure comes closer to the mid-chord, which limits the twist deformation.

Fig. 13 shows the predicted deformation time histories of the flexible foil at $\sigma=2.3$, as well as the $C_{L}$ and $C_{M}$ for both the rigid and flexible foils, over a few sample main cavity shedding periods $T_{o}(=1 / 39 \mathrm{~s}$ for the flexible and $=1 / 43 \mathrm{~s}$ for the rigid hydrofoil). A comparison of the predicted frequency content of the rigid and flexible $C_{L}$ was shown in Fig. 7b. The

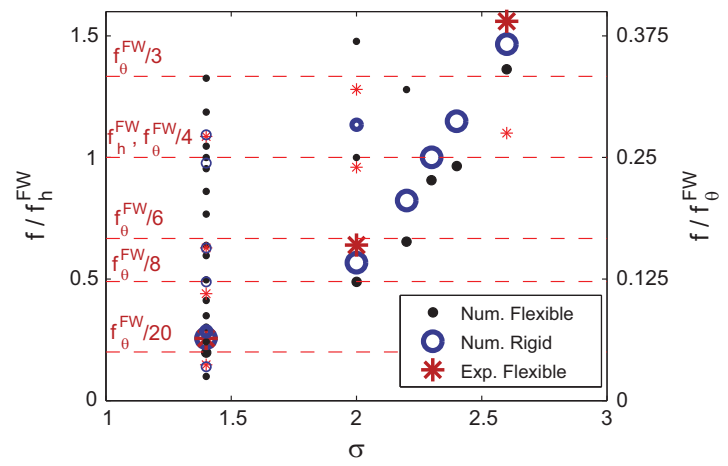

Fig. 9. The effect of the cavitation number $\sigma$ on the predicted and measured significant frequencies of the hydroelastic response. For each case, the cavity shedding frequencies are shown with bigger symbols.

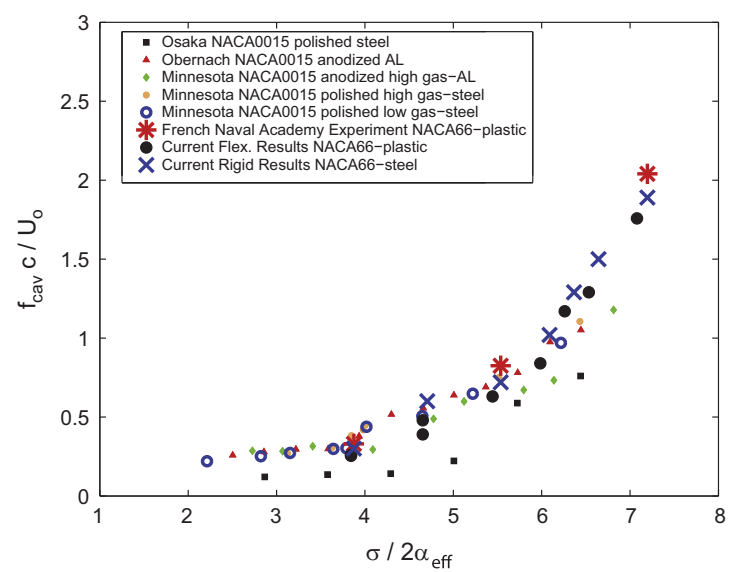

Fig. 10. Numerically evaluated main cavity shedding frequencies compared with various experimental data reported in Kawakami et al. (2008). 
(a)

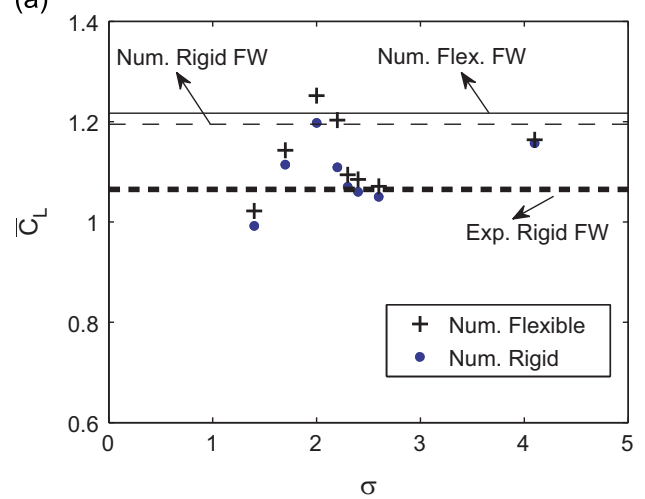

(b)

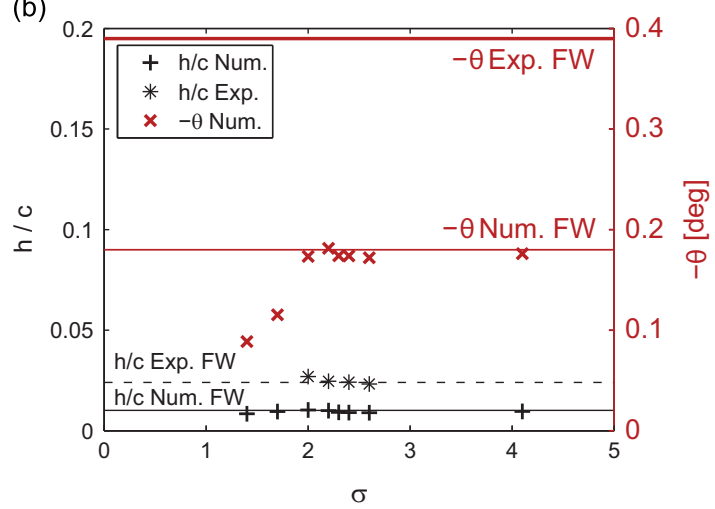

Fig. 11. The effect of $\sigma$ on the numerically computed: (a) mean $C_{L}$, (b) mean bending and twisting deformations. The horizontal lines denote to the predicted and measured values at the FW conditions.

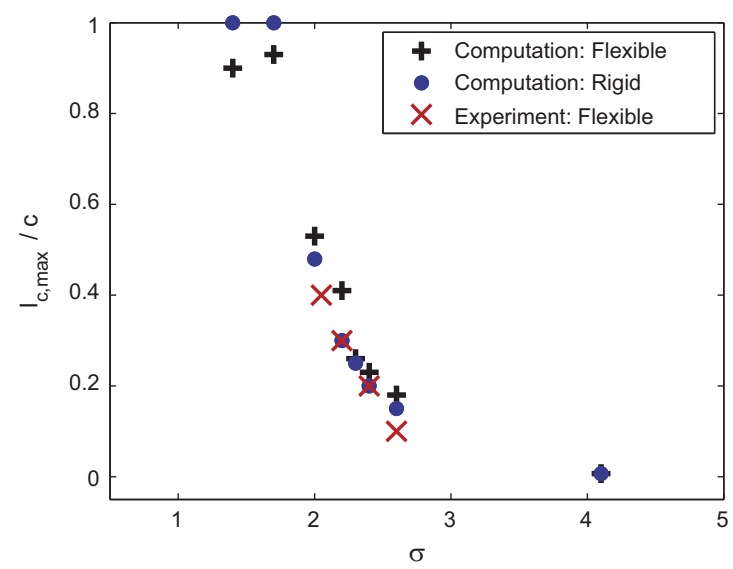

Fig. 12. The effect of $\sigma$ on the numerically computed and experimentally measured maximum attached cavity length.

corresponding cavitation patterns and vorticity contours at times $t_{1}, t_{2}, \ldots, t_{4}$ are shown in Fig. 14. At time $t_{1}$, which is just after the peak values of $C_{L}$ (and $h$ for the flexible hydrofoil), the cavity incepts at the LE, while a small cloud cavity from the previous cycle is still visible. Times $t_{2}$ and $t_{3}$ are after the development of the re-entrant jet (which already broke off the partial cavity at the LE for the rigid foil; the LE partial cavity is still developing for the flexible foil for which the $C_{L}$ and $h$ are near the minimum). Time $t_{4}$ is when the cloud cavity is convecting downstream along the foil surface, and a new LE partial cavity is about to form, and $C_{L}$ and $h$ are near their maximum. Note that for the flexible hydrofoil, $C_{L}$ and $C_{M}$ follow the same trend with $h$ and $\theta$, respectively. Note in Fig. 14 that cavity production is always accompanied with vorticity production.

Fig. 15 shows the same plots as in Fig. 13 for $\sigma=1.4$ with $T_{o}=1 / 8.5 \mathrm{~s}$ for the flexible hydrofoil and $T_{o}=1 / 10 \mathrm{~s}$ for the rigid hydrofoil. Note that for this case, the time histories are not as regular as in the $\sigma=2.3$ case. For example, the plots in Fig. 15 for the flexible hydrofoil show two different cycles (both at a frequency of $1 / T_{o}$ ): there are cycles with high $C_{L}$ and $h$ (between $t / T_{o}=11.4-12.3$ and 12.3-13.2) and with low $C_{L}$ and $h$ (between $t / T_{o}=13.2-14.2$ for the flexible hydrofoil). This complex behavior is caused by small changes in the maximum cavity length for unsteady sheet/cloud cavitation at $\sigma=1.4$. The corresponding predicted cavity patterns and vorticity contours for $\sigma=1.4$ are shown in Fig. 16 at times $t_{1}, t_{2}$, and $t_{3}$. Time $t_{1}$ is near the maximum $C_{L}$ and $h$, while $t_{2}$ is near when the minimum $C_{L}$ and $h$, where a cloud cavity can be observed very close to the foil TE. For the flexible foil, partial shedding of the cavity trailing edge is observed at time $t_{3}$, while for the rigid foil, the re-entrant jet is still growing for the developing LE partial cavity, and the shed cloud cavity from the previous cycle is near the foil trailing edge, which leads to lower $C_{L}$ compared to the flexible foil, as shown in Fig. 15a. Fig. 17 compares the time history of the predicted bending displacement at the tip with the experimentally measured average of the LE and TE displacements at the tip. This experimental data was reported in Benaouicha et al. (2009). Note that although the trends are similar, the predicted bending deformations are lower than the measured ones and the percentage difference is similar to those shown in Table 2; the reasons for these differences were discussed in Section 4.1 and in the Appendix.

Figs. 13 and 15 show that the predicted $C_{L}$ and $C_{M}$ time histories for the rigid and flexible hydrofoils are similar. This is because of the rather small twisting deformations observed in the simulations (the maximum $\theta$ was near $0.22^{\circ}$ for $\sigma=2.3$, and near $0.4^{\circ}$ for $\sigma=1.4$ ). These rather small twisting deformations are obtained because of the relatively high torsional stiffness of the model-scale flexible hydrofoil. Nevertheless, the flexible foil was observed to undergo high frequency load 
(a)

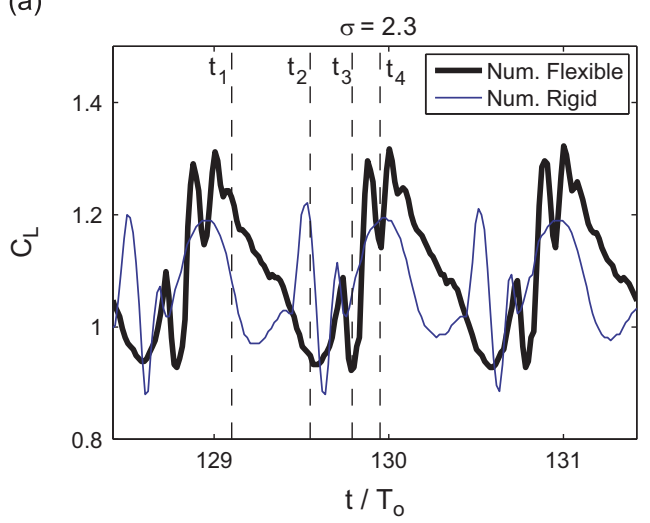

(c)

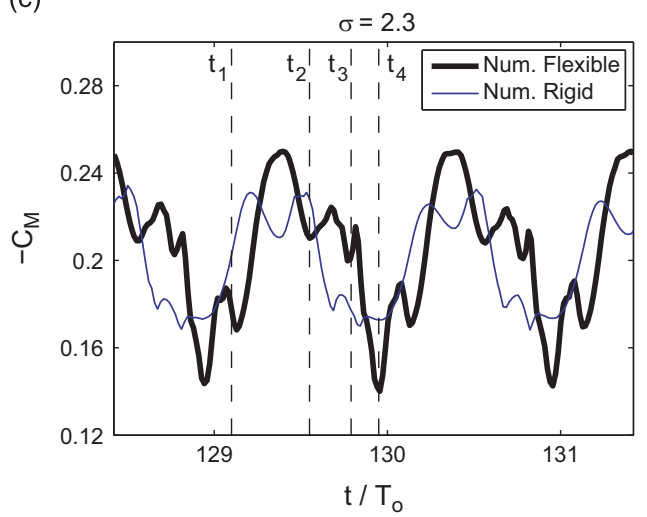

(b)

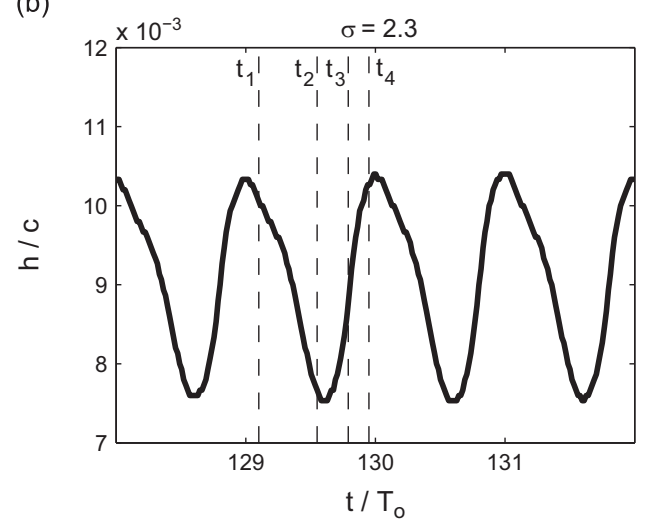

(d)

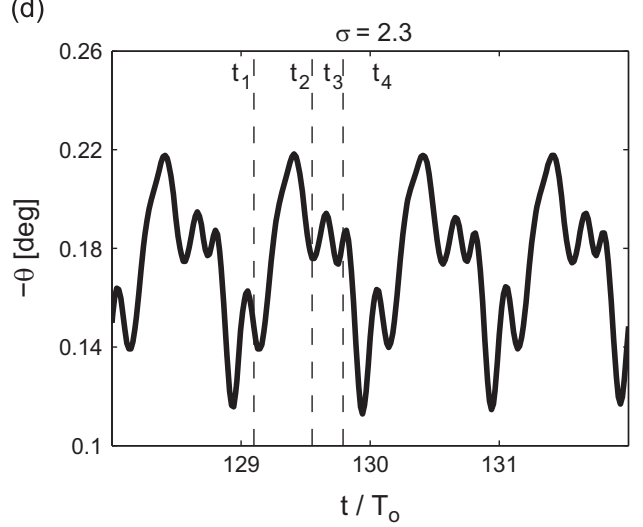

Fig. 13. Comparison of the numerically evaluated sample time histories of $C_{L}$ and $C_{M}$ for the flexible and rigid hydrofoils at $\sigma=2.3$. The bending and twisting time histories of the flexible hydrofoil are also included.

fluctuations induced by the bending and twisting deformations. Also note that the $C_{L}$ and $C_{M}$ time histories of the flexible foil are synchronized with, respectively, the bending and twisting deformation time histories. Another observation is the relative regularity of the time histories for the $\sigma=2.3$ case in comparison to the $\sigma=1.4$ case; this is because the cavity lengths are much longer for $\sigma=1.4$, and this stretched cavity is highly sensitive to flow disturbances and foil deformations, causing non-uniformities over the cavity shedding cycles. The results in Figs. 13 and 15 also show that the time histories of $C_{L}$ and $C_{M}$ are not in phase, because $C_{M}$ values depend both on $C_{L}$ and the center of pressure (ec in Fig. 2), which also varies with the cavity.

Finally, Fig. 18 shows the experimentally observed cavity patterns over the flexible hydrofoil at $\sigma=1.4$. Fig. 18a shows the inception of the sheet cavity at the LE similar to the snapshots at time $t_{2}$ in the numerical result shown in Fig. 16 for both the flexible and rigid hydrofoils. Fig. 18d has a cloud cavity near the hydrofoil TE and a sheet cavity at the LE, which is similar to the $t_{3}$ snapshot shown in Fig. 16 for the flexible hydrofoil.

\subsection{The effect of added-mass oscillations}

When unsteady cavitation develops around a hydrofoil, the mixture density around the hydrofoil would fluctuate. Such fluctuations can induce parametric excitations to the dynamic response of the hydrofoil, since the fluid induced loads on the hydrofoil are proportional to the fluid density, which in turn modify the fluid added inertia, damping, and disturbing forces. The theory of parametric excitations and parametric resonance is a classical topic, and the authors are currently conducting research on their implication on flexible hydrofoils in cavitating flows. However, the followings are some brief results of this ongoing research, without lengthy derivations. Note that the effect of cavitation on hydrofoil dynamical response was previously studied in Benaouicha and Astolfi (2012), De la Torre et al. (2013), De la Torre et al. (2012), and Rajaomazava et al. (2013). These studies reported that the presence of cavitation can change the wetted natural frequencies of a flexible structure.

It can be shown that when a flexible system undergoes parametric excitation at a frequency $f_{\text {cav }}$ in its inertial and/or stiffness terms, there will be additional modulated frequencies $\left|f_{o} \pm n f_{\text {cav }}\right|$, where $n=1,2, \ldots$, in its frequency response, in addition to its main vibration frequency $f_{o}$. For a flexible hydrofoil in cavitating flow, if the main vibration frequency is the cavity shedding frequency itself - i.e. $f_{\text {cav }}$, then there would be additional excited frequencies at $f_{\text {cav }}, 2 f_{\text {cav }}, 3 f_{\text {cav }}, \ldots$. Fig. 7 a-d 


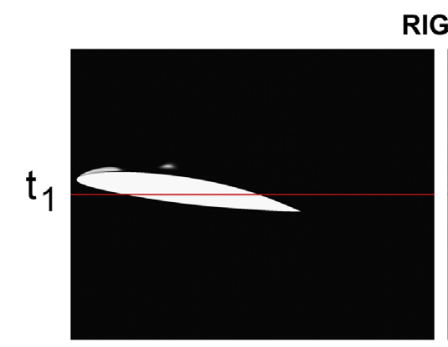

RIGID
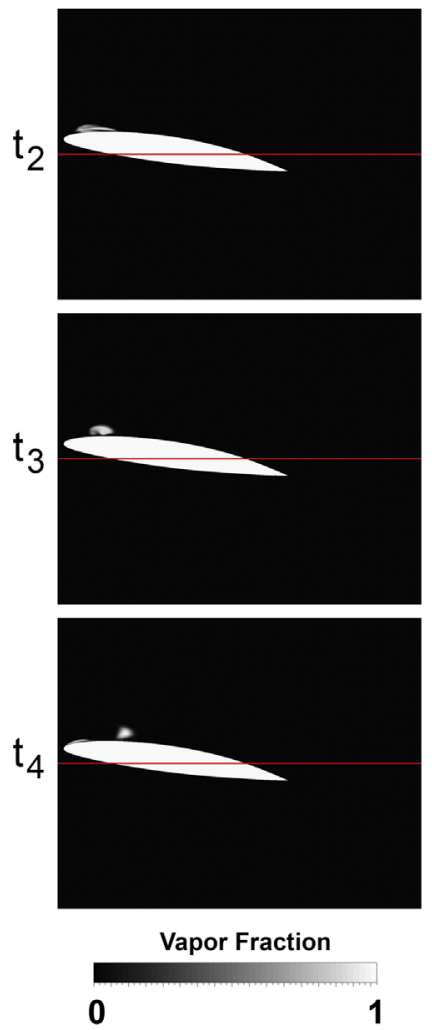
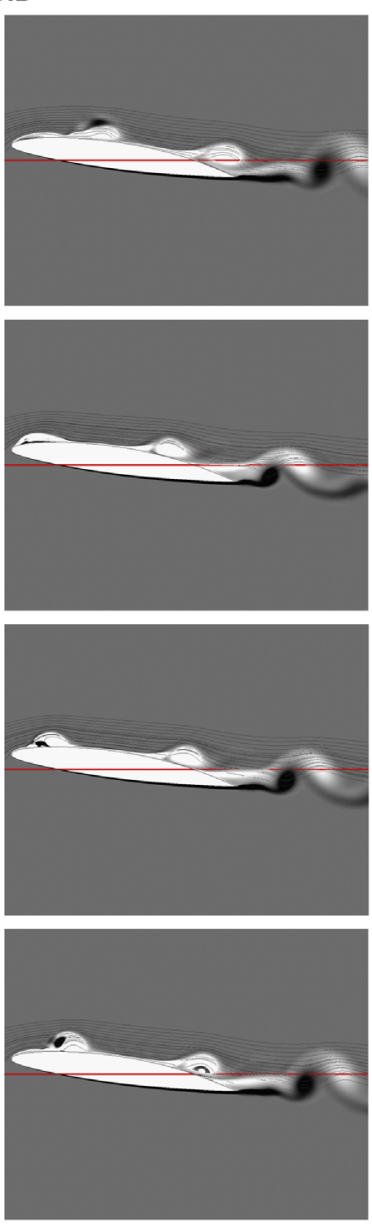

Vorticity $[1 / \mathrm{s}]$

$-500$
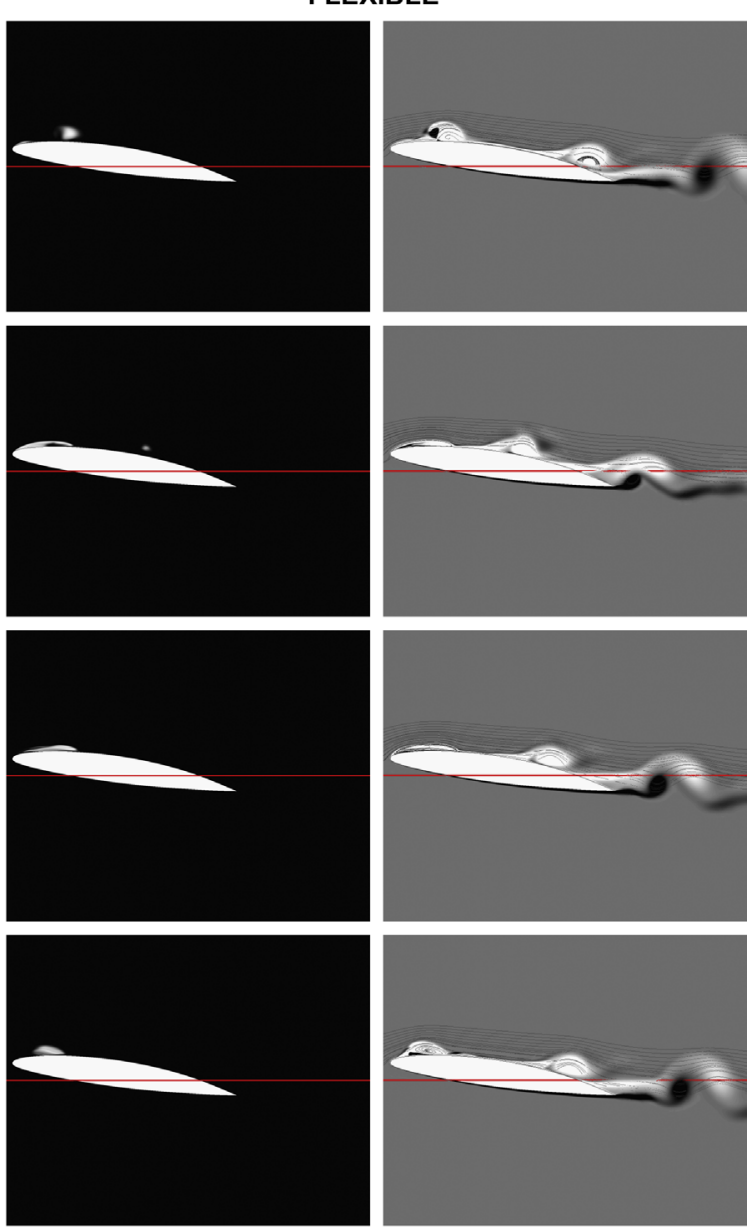

Vapor Fraction

0

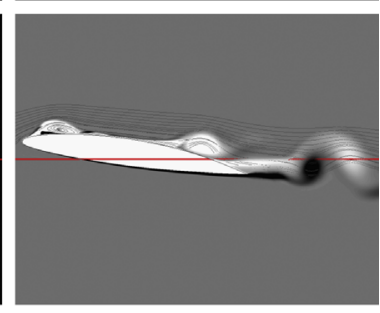

Vorticity [1/s]

$-500$

500

Fig. 14. Vapor fraction and vorticity pattern plots for the rigid and flexible hydrofoils at $\sigma=2.3$.

reveals that frequency spectrum of $C_{L}$ of the flexible hydrofoil in cavitating flows shows this theorized behavior. These findings are similar to the frequency modulation findings reported in Rajaomazava et al. (2013).

Generally speaking, added-mass oscillations broaden the frequency response of the hydrofoil. The implications of these additional modulated frequencies (e.g. possibility of parametric resonance) are a topic of an ongoing research.

\section{Conclusions and future work}

A numerical framework has been developed to analyze the coupled effects of structural vibrations and viscous cavitating flows on hydrofoils. The simulation has been validated with experimentally measured hydrodynamic coefficients of a rigid hydrofoil, in addition to the experimentally measured frequency response, cavitation pattern, and maximum cavity length of a flexible hydrofoil in a cavitation tunnel at the French Naval Academy. In general, reasonable agreement was observed between numerical predictions and experimental measurements of the frequency response of the vibrating hydrofoil, and between the predicted and observed cavitation patterns and maximum cavity length. However, some discrepancies were observed for the magnitudes of the induced deformations; this might be partly due to the 2-D flow assumption which ignored the 3-D effects (including the influence of tip gap flow, boundary layer effect at the wall, and induced drag, for a foil with a span to chord aspect ratio of 1.27), and the use of the generalized 3-D structural model. The following observations had been made:

(i) The vibration frequencies of the flexible hydrofoil in cavitating flows were observed to focus/lock-in to the subharmonic frequencies of its wetted natural frequencies. 
(a)

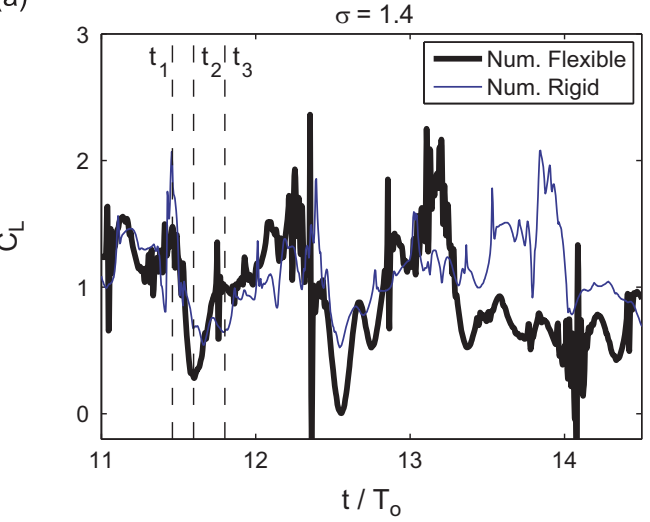

(c)

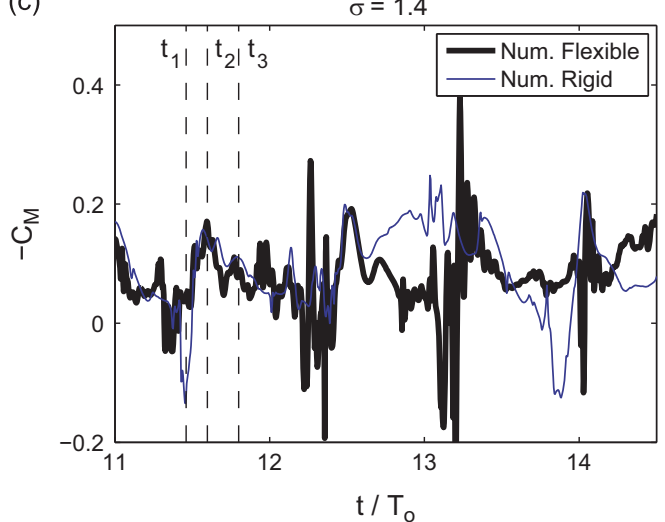

(b)

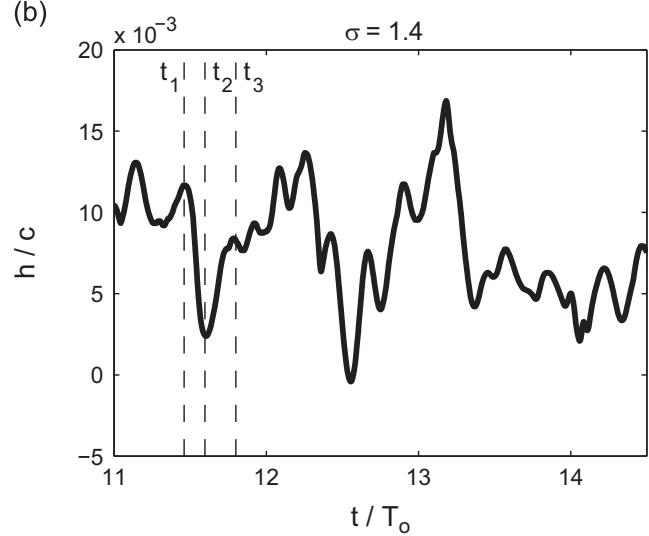

(d)

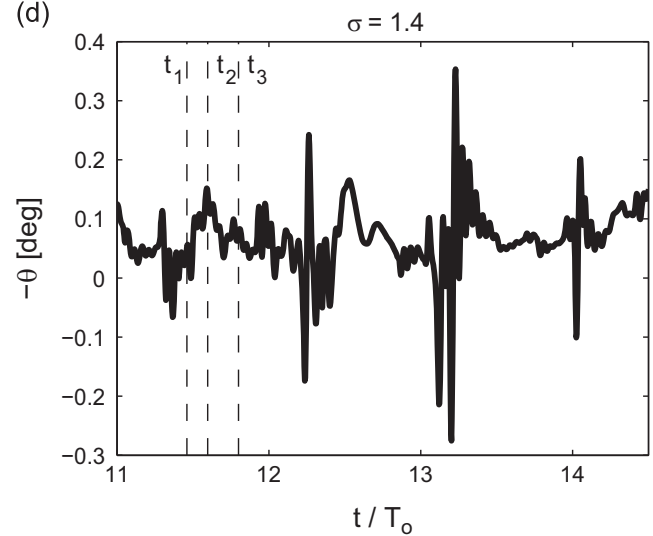

Fig. 15. Comparison of the numerically evaluated sample time histories of $C_{L}$ and $C_{M}$ for the flexible and rigid hydrofoils at $\sigma=1.4$. The bending and twisting time histories of the flexible hydrofoil are also included.
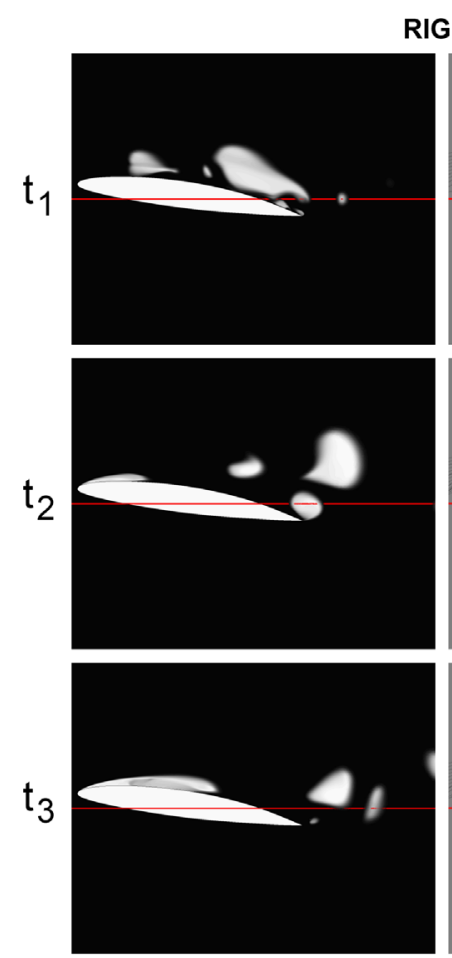

Vapor Fraction
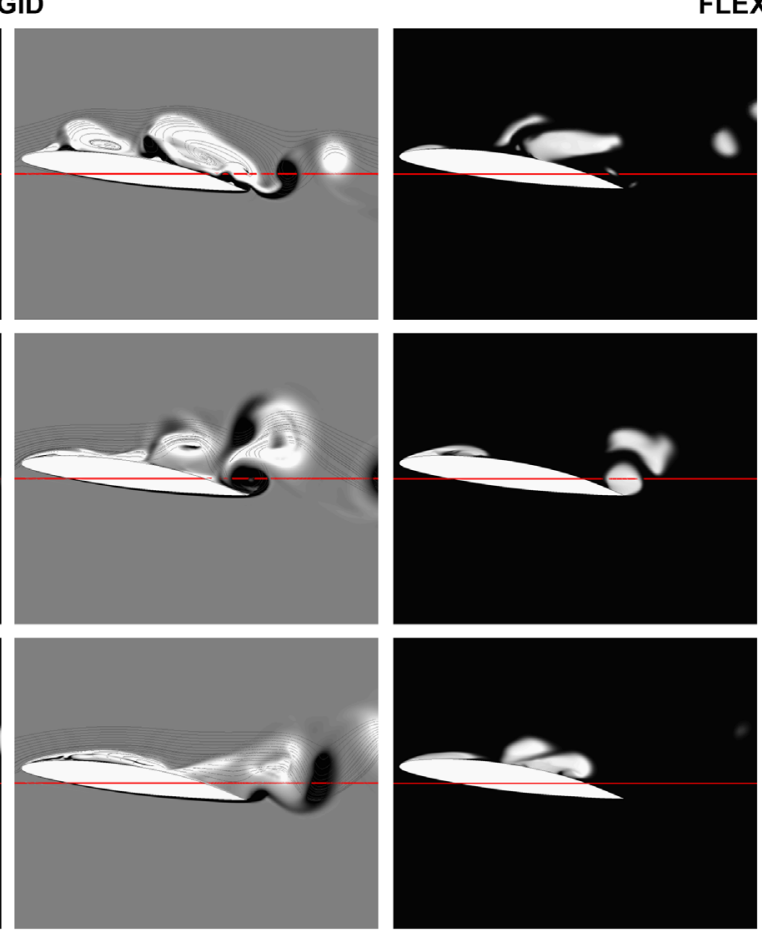

Vapor Fraction
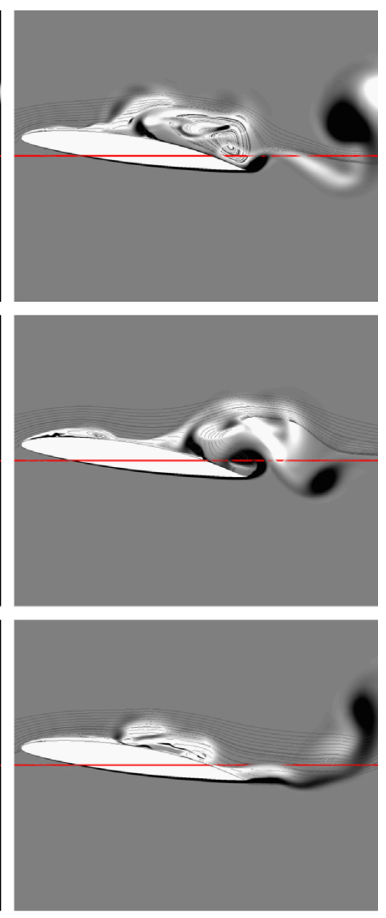

Vorticity [1/s]

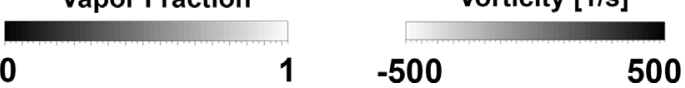

Fig. 16. Vapor fraction and vorticity pattern plots for the rigid and flexible hydrofoils at $\sigma=1.4$. 


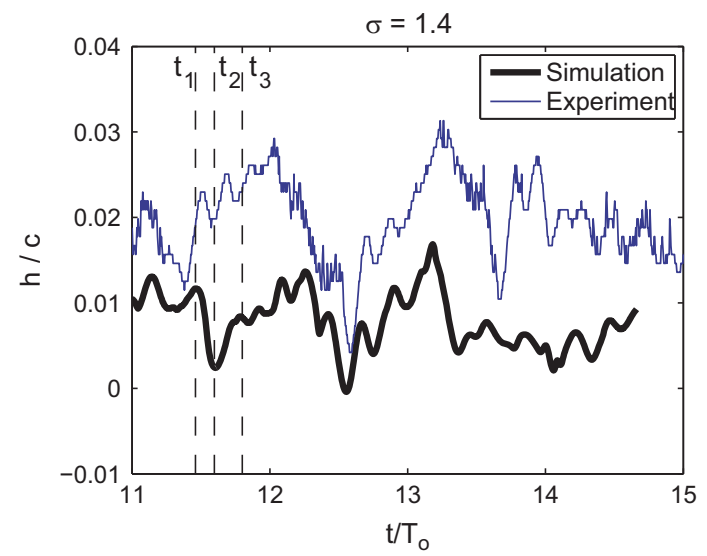

Fig. 17. Comparison of the numerically and experimentally measured time histories of the bending displacement of the flexible hydrofoil at $\sigma=1.4$. The experimental displacement [reported in Benaouicha et al. (2009)] is the average of the leading and trailing edge displacements.

(a)

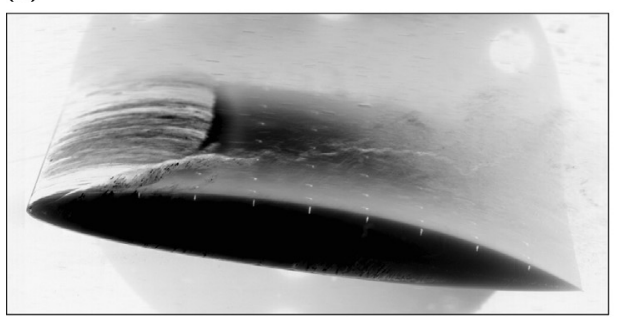

(c)

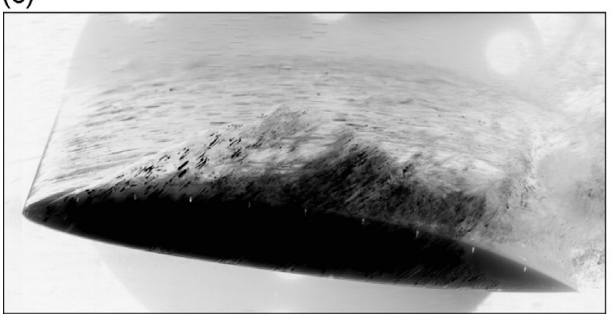

(b)

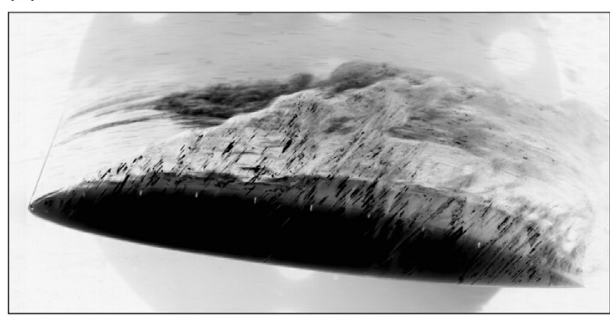

(d)

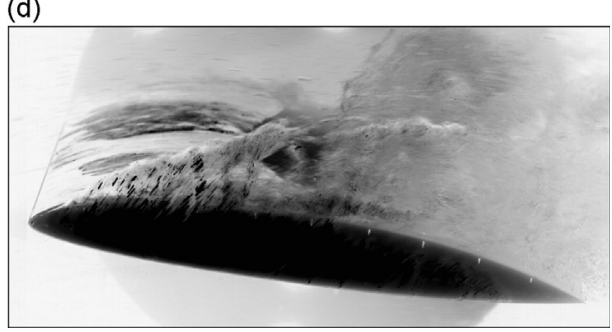

Fig. 18. Sample cavitation patterns recorded from the experiments at $\sigma=1.4$ on the flexible hydrofoil.

(ii) For flexible hydrofoils made of an isotropic material, if the center of pressure is at an upstream location relative to the elastic axis, this leads to a clockwise twisting motion that increases the effective angle-of-attack. This yields higher lift coefficients for the flexible hydrofoil relative to the rigid hydrofoil.

(iii) The frequency content of the hydrodynamic load coefficients in the cavitation regime with low cavitational numbers $(\sigma<2.0)$ was broader and noisier than with high cavitational numbers $(\sigma>2.0)$.

(iv) The effect of cavitation was observed to cause frequency modulation in the dynamic response of the flexible hydrofoil, as the fluid-induced added mass fluctuated with unsteady cavitation.

As for future work, more experiments involving flexible hydrofoils would be beneficial as the deformations in the current experiments were limited. Additional studies are underway on how cavitating flow may induce parametric excitations to flexible structures and their possible implications.

\section{Acknowledgment}

The authors gratefully acknowledge Ms. Kelly Cooper (program manager) and the Office of Naval Research (ONR), for their financial support through Grant nos. N00014-11-1-0833 and N0014-12-C-0585, as well as ONR Global and Dr. WoeiMin Lin (program manager) through grant no. N62909-12-1-7076. 


\section{Appendix - Derivation of the solid equations of motion}

Using Eqs. (6) and (7), and for $\left(x_{\theta}, y_{\theta}\right)=(0,0)$, the kinetic $(K)$ and elastic $(V)$ energy of the 2-DOF system in Fig. 2 can be expressed as

$$
\begin{aligned}
& K=\int_{0}^{s} \frac{1}{2} m^{\prime}(f(z) \dot{\bar{h}}(t))^{2} d z+\int_{0}^{s} \frac{1}{2} I_{\theta}^{\prime}(g(z) \dot{\bar{\theta}}(t))^{2} d z \\
& \left.V=\int_{0}^{s} \frac{1}{2} E_{s} I^{\prime} \frac{d^{2} f(z)}{d z^{2}} \bar{h}(t)\right)^{2} d z+\int_{0}^{s} \frac{1}{2} G_{s} J^{\prime}\left(\frac{d g(z)}{d z} \bar{\theta}(t)\right)^{2} d z,
\end{aligned}
$$

where $m^{\prime}$ and $I_{\theta}^{\prime}$ are the mass and moment of inertia (along the elastic axis E.A.) of the hydrofoil per unit span; $E_{s}$ is Young's modulus; $G_{s}$ is the torsional rigidity of the hydrofoil; $J^{\prime}$ is the torsion constant of the hydrofoil cross-section along E.A; and $I^{\prime}$ is the 2 nd moment of area of the hydrofoil cross-section about its thickness and about E.A. Hence, the Lagrangian (LA) of the system is

$$
L A=K-V .
$$

Using Eq. (A.3) and after including the generalized forces due to the virtual work of the external forces and moments (including the fluid forces and material damping effects), the equations of motion of the hydrofoil in terms of the generalized coordinates $\bar{h}$ and $\bar{\theta}$ are

$$
\begin{aligned}
& \frac{d}{d t}\left(\frac{\partial L A}{\partial \overline{\bar{h}}}\right)-\frac{\partial L A}{\partial \bar{h}}=\frac{\left(\int_{0}^{s} L^{\prime} \delta h d z-\int_{0}^{s} C_{h}^{\prime} \dot{h} \delta h d z\right)}{\delta \bar{h}} \\
& \rightarrow \tilde{m} \ddot{\bar{h}}+\tilde{C}_{h} \dot{\bar{h}}+\tilde{K}_{h} \bar{h}=\tilde{L}, \\
& \frac{d}{d t}\left(\frac{\partial L A}{\partial \dot{\bar{\theta}}}\right)-\frac{\partial L A}{\partial \bar{\theta}}=\frac{\left(\int_{0}^{s} T^{\prime} \delta \theta d z-\int_{0}^{s} C_{\theta}^{\prime} \dot{\theta} \delta \theta d z\right)}{\delta \bar{\theta}} \\
& \rightarrow \tilde{I}_{\theta} \ddot{\bar{\theta}}+\tilde{C}_{\theta} \dot{\bar{\theta}}+\tilde{K}_{\theta} \bar{\theta}=\tilde{T},
\end{aligned}
$$

where $L^{\prime}$ and $T^{\prime}$ are the 2-D (per unit span) net lift and fluid-induced moment along the E.A. and $C_{h}{ }^{\prime}$ and $C_{\theta}{ }^{\prime}$ are the 2-D material damping constants (per unit span) against bending and twisting deformations, respectively. In Eqs. (A.4) and (A.5), the 'generalized' mass, stiffness, and damping terms are given as

$$
\begin{aligned}
& \tilde{m}=\int_{0}^{s} m^{\prime}(f(z))^{2} d z=m^{\prime} \int_{0}^{s}(f(z))^{2} d z=m^{\prime} s_{f f}, \\
& \tilde{I}_{\theta}=\int_{0}^{s} I_{\theta}^{\prime}(g(z))^{2} d z=I_{\theta}^{\prime} \int_{0}^{s}(g(z))^{2} d z=I_{\theta}^{\prime} s_{g g}, \\
& \tilde{K}_{h}=\int_{0}^{s} E_{s} I^{\prime}\left(\frac{d^{2} f(z)}{d z^{2}}\right)^{2} d z=\tilde{m}\left(2 \pi f_{h}^{a}\right)^{2}=m^{\prime} s_{f f}\left(2 \pi f_{h}^{a}\right)^{2} \\
& \tilde{K}_{\theta}=\int_{0}^{s} G_{s} J^{\prime}\left(\frac{d g(z)}{d z}\right)^{2} d z=\tilde{I}_{\theta}\left(2 \pi f_{\theta}^{a}\right)^{2}=I_{\theta}^{\prime} s_{g g}\left(2 \pi f_{\theta}^{a}\right)^{2}, \\
& \tilde{C}_{h}=\int_{0}^{s} C_{h}^{\prime}(f(z))^{2} d z=2 \zeta_{h} \tilde{m}\left(2 \pi f_{h}^{a}\right)=2 \zeta_{h} m^{\prime}\left(2 \pi f_{h}^{a}\right) s_{f f}, \\
& \tilde{C}_{\theta}=\int_{0}^{s} C_{\theta}^{\prime}(g(z))^{2} d z=2 \zeta_{\theta} \tilde{I}_{\theta}\left(2 \pi f_{\theta}^{a}\right)=2 \zeta_{\theta} I_{\theta}^{\prime}\left(2 \pi f_{\theta}^{a}\right) s_{g g},
\end{aligned}
$$

where $f_{h}^{a}$ and $f_{\theta}^{a}$ are respectively the 1 st bending and torsional natural frequencies of the hydrofoil in air, and $\zeta_{h}$ and $\zeta_{\theta}$ are respectively the damping factors for the bending and twisting DOFs in air. Note that Eqs. (A.6) and (A.7) imply

$$
\begin{aligned}
& s_{f f}=\int_{0}^{s}(f(z))^{2} d z, \\
& s_{g g}=\int_{0}^{s}(g(z))^{2} d z .
\end{aligned}
$$


Similarly, the 'generalized' lift and moment terms in Eqs. (A.4) and (A.5) are approximated as

$$
\begin{aligned}
& \tilde{L}=\int_{0}^{s} L^{\prime} f(z) d z \approx L^{\prime} s_{f f}, \\
& \tilde{T}=\int_{0}^{s} T^{\prime} g(z) d z \approx T^{\prime} s_{g g} .
\end{aligned}
$$

Eqs. (A.14) and (A.15) assume that the leading order terms in $L^{\prime}$ are dependent on $h, d h / d t, d^{2} h / d t^{2}$, and in $T^{\prime}$ are dependent on $\theta, d \theta / d t, d^{2} \theta / d t^{2}$. However, this assumption is not strictly true since $L^{\prime}$ and $T^{\prime}$ may have other dependencies: for example $L^{\prime}$ would also depend on $\alpha_{e f f}\left(=\alpha_{o}-\alpha_{L o}-\theta\right.$, the effective angle of attack of the foil, where $\alpha_{L o}$ is the hydrofoil camber angle for which the net lift force is zero). Using potential flow theory, an order of magnitude analysis would show that at the leading order

$$
\begin{aligned}
& L^{\prime} \approx O(\ddot{h})+O\left(\frac{\dot{h}}{k}\right)+O\left(\frac{\dot{\theta}}{k}\right)+O\left(\frac{\alpha_{e f f}}{k^{2}}\right), \\
& T^{\prime} \approx O(\ddot{\theta})+O\left(\frac{\dot{h}}{k}\right)+O\left(\frac{\dot{\theta}}{k}\right)+O\left(\frac{\alpha_{e f f}}{k^{2}}\right),
\end{aligned}
$$

where $k=\omega b / U_{o} \sim O(1)$ ( $\omega$ being the primary vibration frequency). Theoretically, $\tilde{L}$ and $\tilde{T}$ should be evaluated from the integral operations shown in the first equalities given in Eqs. (A.14) and (A.15); the result of these operations would depend on each of the functional dependency of $L^{\prime}$ and $T^{\prime}$, unlike the approximate results given in the same equations. However, the computational fluid dynamics calculations in the simulations only gives lumped $L^{\prime}$ and $T^{\prime}$ values without revealing how they depend on $h, \theta$, their derivatives, and $\alpha_{e f f}$, and this puts a restriction against properly treating each of the different dependencies of $L^{\prime}$ and $T^{\prime}$ in Eqs. (A.14) and (A.15). Hence, the assumptions stated in Eqs. (A.14) and (A.15) has been made; these assumptions would result in the same frequency content of the dynamic response between the experiment and the simulation (since the frequency content would primarily depend on the $d^{2} h / d t^{2}$ dependency of $L^{\prime}$ and the $d^{2} \theta / d t^{2}$ dependency of $T^{\prime}$ ), but, based on potential flow theory, these assumptions are projected to underestimate the elastic deformations by $36 \%$ and $23 \%$, respectively (since these assumptions would underestimate the $O\left(\alpha_{e f f} / k^{2}\right)$ dependencies of $L^{\prime}$ and $T^{\prime}$ ).

The authors attribute the further discrepancies between the predicted and measured deformations to slight variations in the $f$ and $g$ functions (given in Fig. 3) with changes in the effective angle of attack.

\section{References}

Abramson, H.N., 1969. Hydroelasticity review of hydrofoil flutter. Applied Mechanics Reviews 22 (2), $115-121$.

Akcabay, D.T., Ducoin, A., Chae, E.J., Young, Y.L., 2012. Transient hydroelastic response of a flexible hydrofoil in subcavitating and cavitating flows. In: Proceedings of the 29th Symposium on Naval Hydrodynamics Gothenburg, Sweden, 26-31 August 2012.

Akcabay, D.T., Young, Y.L., 2014. Influence of cavitation on the hydroelastic stability of hydrofoils. Journal of Fluids and Structures. In press, http://dx.doi.org/ 10.1016/j.jfluidstructs.2014.04.010.

Amromin, E., Kovinskaya, S., 2000. Vibration of cavitating elastic wing in a periodically perturbed flow: excitation of subharmonics. Journal of Fluids and Structures 14 (5), 735-751.

Amromin, E.L., 2014. Design approach for cavitation tolerant hydrofoils and blades. Journal of Fluids and Structures 45, $96-106$.

ANSYS, 2011. ANSYS CFX-Solver Modeling Guide. Release 14.0, ANSYS, Inc. Canonsburg, PA, USA.

Arndt, R.E.A., Wosnik, M., 2008. Towards the control of cavitating flows. In: Proceedings of the 12th International Symposium on Transport Phenomena and Dynamics of Rotating Machinery, February 17-22, Honolulu, HW, USA. ISROMAC12-2008-20017. ISBN: 9781605604879.

Arndt, R.E.A., 2012. Some remarks on hydrofoil cavitation. Journal of Hydrodynamics 24 (3), 305-314.

Ausoni, P., Escaler, X., Avellan, F., Egusquiza, E., Farhat, M., 2007. Cavitation influence on von Kármán vortex shedding and induced hydrofoil vibrations. Journal of Fluids Engineering 129 (8), 966-973.

Benaouicha, M., Ducoin, A., Frikha, S., Astolfi, J.-A., Debecdelievre, H., 2009. Etude Numérique et Expérimentale du Comportement Hydroélastique d'un Hydrofoil dans un Écoulement Cavitant. In: Proceedings of 19ème Congrès Français de Mécanique (CFM2009), Marseille, France, August, pp. 24-28. Persistent URL: 〈http://hdl.handle.net/2042/36624〉.

Benaouicha, M., Astolfi, J.-A., 2012. Analysis of added mass in cavitating flow. Journal of Fluids and Structures 31, 30-48.

Besch, P.K., 1969. Flutter and cavity-induced oscillation of a two-degree-of-freedom hydrofoil in two-dimensional cavitating flow. Report no. 3000, Department of Navy, Naval Ship Research and Development Center, Hydromechanics Laboratory Research and Development Report, Washington, DC 20007, USA. Persistent URL: 〈http://hdl.handle.net/1721.3/49298〉.

Bisplinghoff, R.L., Ashley, H., Halfman, R.L., 1955. Aeroelasticity. Addison-Wesley, Reading, MA, USA.

Brennen, C., Oey, K.T., Babcock, C.D., 1980. Leading-edge flutter of supercavitating hydrofoils. Journal of Ship Research 24 (3), $135-146$.

Brennen, C.E., 1995. Cavitation and Bubble Dynamics. Oxford University Press, Inc., New York, NY, USA, ISBN: 0195094093.

Chae, E.J., Akcabay, D.T., Young, Y.L., 2013. Dynamic response and stability of a flapping foil in a dense and viscous fluid. Physics of Fluids 25, 104106.

Coutier-Delgosha, O., Reboud, J.L., Fortes-Patella, R., 2003. Evaluation of the turbulence model influence on the numerical simulations of unsteady cavitation. Journal of Fluids Engineering 125 (1), 38-45.

De la Torre, O., Escaler, X., Egusquiza, E., Dreyer, M., Farhat, M., 2012. The effect of cavitation on the natural frequencies of a hydrofoil. In: Proceedings of the 8th International Symposium on Cavitation, CAV2012, August 13-16, Singapore. Submission No. 95. ISBN: 978-981-07-2826-7.

De la Torre, O., Escaler, X., Egusquiza, E., Farhat, M., 2013. Experimental investigation of added mass effects on a hydrofoil under cavitation conditions. Journal of Fluids and Structures 39, 173-187.

Ducoin, A., Young, Y.L., Sigrist, J.F., 2010. Hydroelastic response of a flexible hydrofoil in turbulent, cavitating flow. In: ASME 2010: Proceedings of the 7th International Symposium on Fluid-Structure Interactions, Flow-Sound Interactions, and Flow-Induced Vibration \& Noise, August 1-5, Montreal, Canada. Paper No. FEDSM-ICNMM2010-30310, 493-502. ISBN: 978-0-7918-5451-8. 
Ducoin, A., Young, Y.L., 2011. Hydroelastic response and stability of a hydrofoil in viscous flow. In: Proceedings of the Second International Symposium on Marine Propulsors (SMP'11), June 15-17, Hamburg, Germany, p. 294. ISBN: 978-3-86342-236-3.

Ducoin, A., Astolfi, J.A., Sigrist, J.-F., 2012a. An experimental analysis of fluid structure interaction on a flexible hydrofoil in various flow regimes including cavitating flow. European Journal of Mechanics - B/Fluids 36, 63-74.

Ducoin, A., Huang, B., Young, Y.L., 2012b. Numerical modeling of unsteady cavitating flows around a stationary hydrofoil. International Journal of Rotating Machinery 2012, 215678, http://dx.doi.org/10.1155/2012/215678.

Ducoin, A., Young, Y.L., 2013. Hydroelastic response and stability of a hydrofoil in viscous flow. Journal of Fluids and Structures 38, 40-57.

Forster, C., Wall, W.A., Ramm, E., 2007. Artificial added mass instabilities in sequential staggered coupling of nonlinear structures and incompressible viscous flows. Computer Methods in Applied Mechanics and Engineering 196 (7), 1278-1293.

Franc, J.P., Michel, J.M., 1988. Unsteady attached cavitation on an oscillating hydrofoil. Journal of Fluid Mechanics 193, 171-189.

Franc, J.-P., Michel, J.-M., 2005. Fundamentals of Cavitation (Fluid Mechanics and Its Applications). Springer, Netherlands http://dx.doi.org/10.1007/1-40202233-6.

Franc, J.-P., 2006. Physics and control of cavitation. In: Design and Analysis of High Speed Pumps. Educational Notes RTO-EN-AVT-143, Paper 2, Neuilly-surSeine, France: RTO, pp. 2-1-2-36. Available at 〈http://www.cso.nato.int/abstracts.aspx〉.

Fung, Y.C., 2008. An Introduction to the Theory of Aeroelasticity. Dover Publications, Mineola, New York, USA.

Harwood, C., Ducoin, A., Young, Y.L., 2012. Influence of gap flow on the cavitating response of a rectangular hydrofoil. In: Propeller and Shafting Symposium, September 11-12, Norfolk, VA, USA.

Harwood, C., Young, Y.L., 2014. A physics-based gap-flow model for potential flow solvers. Ocean Engineering. In press, http://dx.doi.org/10.1016/j.oceaneng. 2014.03.025.

Huang, B., Ducoin, A., Young, Y.L., 2012. Evaluation of cavitation models for prediction of transient cavitating flows around a stationary and a pitching hydrofoil. In: Proceedings of the 8th International Symposium on Cavitation (CAV2012), August 13-16, 2012, Singapore. ISBN: 978-981-07-2826-7.

Huang, B., Ducoin, A., Young, Y.L., 2013. Physical and numerical investigation of cavitating flows around a pitching hydrofoil. Physics of Fluids 25, 102109.

Kaplan, P., Lehman, A.F., 1966. Experimental studies of hydroelastic instabilities of cavitating hydrofoils. Journal of Aircraft 3 (3), $262-269$.

Karim, M.M., Mostafa, N., Sarker, M.M.A., 2010. Numerical study of unsteady flow around a cavitating hydrofoil. Journal of Naval Architecture and Marine Engineering 7 (2), 51-60.

Kato, K., Dan, H., Matsudaira, Y., 2006. Lock-in phenomenon of pitching hydrofoil with cavitation breakdown (unsteady fluid force characteristics and visualization of flow structure). JSME International Journal Series B Fluids and Thermal Engineering 49 (3), $797-805$.

Kawakami, D.T., Fuji, A., Tsujimoto, Y., Arndt, R.E., 2008. An assessment of the influence of environmental factors on cavitation instabilities. Journal of Fluids Engineering 130 (3), 031303.

Leroux, J.-B., Astolfi, J.A., Billard, J.Y., 2004. An experimental study of unsteady partial cavitation. Journal of Fluids Engineering 126 (1), 94-101.

Liu, Z., Young, Y.L., 2009. Utilization of bend-twist coupling for performance enhancement of composite marine propellers. Journal of Fluids and Structures 25 (6), 1102-1116.

Menter, F.R., 1992. Improved Two-Equation $k-\omega$ Turbulence Models for Aerodynamic Flows. Technical Memorandum. National Aeronautics and Space Administration, Washington, DC 20546, USA.

Mostafa, M.N.E., Karim, M.M., Sarker, M.M.A., 2012. Numerical study of unsteady behavior of partial cavitation on two dimensional hydrofoils. Journal of Shipping and Ocean Engineering 2 (1), 10-17.

Motley, M.R., Liu, Z., Young, Y.L., 2009. Utilizing fluid-structure interactions to improve energy efficiency of composite marine propellers in spatially varying wake. Composite Structures 90 (3), 304-313.

Rajaomazava III, T.E., Benaouicha, M., Astolfi, J.-A., 2013. Structure dynamics analysis in inhomogeneous density flows. In: Proceedings of the ASME 2013 Pressure Vessels and Piping Conference (PVP2013), Vol. 4, July 14-18, Paris, France. Paper No. PVP2013-97637. ISBN: 978-0-7918-5568-3. http://dx.doi. org/10.1115/PVP2013-97637.

Reboud, J.L., Stutz, B., Coutier-Delgosha, O., 1998. Two phase flow structure of cavitation: experiment and modeling of unsteady effects. In: Proceedings of the 3rd International Symposium on Cavitation, Grenoble, France.

Saito, Y., Takami, R., Nakamori, I., Ikohagi, T., 2007. Numerical analysis of unsteady cloud cavitation around a NACA0015 foil. Computational Mechanics 40 (1), 85-96.

Sears, W.R., 1941. Some aspects of non-stationary airfoil theory and its practical applications. Journal of Aeronautical Sciences (Institute of the Aeronautical Sciences) 8 (3), 104-108.

Sedlar, M., Komarek, M., Vyroubal, M., Muller, M., 2012. Experimental and numerical analysis of cavitating flow around a hydrofoil. EPJ Web of Conferences 25, 01084, http://dx.doi.org/10.1051/epjconf/20122501084.

Seo, J.H., Lele, S.K., 2009. Numerical investigation of cloud cavitation and cavitation noise on a hydrofoil section. In: Proceedings of the 7th International Symposium on Cavitation (CAV 2009), August 17-22, Ann Arbor, MI, USA. Paper No. CAV2009-0062. Persistent URL: 〈http://hdl.handle.net/2027.42/ 84259>.

Song, C.C.S., 1969. Vibration of Cavitating Hydrofoils. Project Report No. 111, University of Minnesota St. Anthony Falls Hydraulic Laboratory, Minneapolis, M. N., U.S.A., Persistent URL: 〈http://hdl.handle.net/11299/108329〉.

Sun, H., 2012. Numerical Study of Hydrofoil Geometry Effect on Cavitating Flow. Journal of Mechanical Science and Technology 26 (8), $2535-2545$.

Theodorsen, T., 1935. General Theory of Aerodynamic Instability and the Mechanisms of Flutter. Report No. 496, National Advisory Committee for Aeronautics, U.S.A., Persistent URL: 〈http://hdl.handle.net/2060/19930090935〉.

Young, Y.L., 2007. Time-dependent hydroelastic analysis of cavitating propulsors. Journal of Fluids and Structures 23 (2), $269-295$.

Young, Y.L., 2008. Fluid-structure interaction analysis of flexible composite marine propellers. Journal of Fluids and Structures 24 (6), $799-818$.

Young, Y.L., Chae, E.J., Akcabay, D.T., 2012. Hybrid algorithm for modeling of fluid-structure interaction in incompressible, viscous flows. Acta Mechanica Sinica 28 (4), 1030-1041.

Zwart, P., Gerber, A., Belamri, T., 2004. A two-phase flow model for predicting cavitation dynamics. In: Proceedings of the 5th International Conference on Multiphase Flow, Yokohama, Japan, May 30-June 4. 